\title{
Auge und Rückenmark *)
}

\author{
Von \\ Dr. Rieger in Würzburg \\ und \\ Dr. von Forster in Nürnberg.
}

Die reiche Gelegenheit, Erkrankungen der Sehnerven an Patienten mit spinalen Symptomen zu beobachten, die wir in Würzburg sowohl im Juliusspital als in der UniversitätsAugenklinik fanden, legte es uns nahe, den Causalnexus zwisehen den beiden räumlich weit getrennten Krankheitslocalisationen im Rückenmark und Auge näher zu verfolgen, unsere Casuistik unter diesem Gesichtspunkte zu betrachten und für Verschiedenes das Thierexperiment zu Hülfe zu nehmen.

*) Herrn Prof. Michel, der uns nicht nur in liberalster Weise alles für uns werthvolle Krankenmaterial der Augenklinik zur Verfügung stellte, sondern auch unsere ganze Arbeit jederzeit mit lebhaftestem Interesse begleitete, sprechen wir hier unsern wärmsten Dank aus, ebenso Herrn Geheimrath v. Rinecker, dessen freundlicher Erlaubniss wir die Beobachtungen auf der psychiatrischen Klinik verdanken. Zu ganz besonderem Dank haben uns die Herren Professoren Fick und Rossbach verpllichtet als Vorstände des physilologisehen und pharmakologischen Instituts, in welchen wir je einen Theil unserer Versuche arsführten. 
Sehr bald musste die theils stillschweigend, theils ausdrücklich gemachte Annahme*) bedenklich erscheinen, dass bei einer oculare Symptome bietenden Rückenmarlsskrankheit, und zwar gleichgültig welcher Bestandtheil der Symptomentrias, Opticusaffection, Muskellähmung, Pupillenphänomene, ihre anatomische Localisation immer in einem hypothetisch zu supponirenden Mitergriffensein von Hirntheilen zu suchen sei. Die im Laufe der letzten Jahre an den zahlreichen Paralytikem der hiesigen Irrenabtheilung gemachte Beobachtung, dass gerade und ausschliesslich diejenigen unter ihnen oculare Symptome boten, bei welchen das Fehlen des Patellarreflexes, resp. auch hochgradige Steigerung desselben, sowie andere unzweideutig spinale Symptome ein Mitergriffensein des Rïckenmarks documentirten, musste ihrerseits zu dem Sehlusse drängen, dass bei den in Rede stehenden Augenaffectionen nicht das Hirn, sondern das Rückenmark in erster Linie in Betracht kommt, denn andererseits waren Patienten, die p. mort. hochgradigste Leptomeningitis und Atrophie der ganzen Hirnconvexität boten, aber bei intactem Rückenmark, immer frei von ocularen Störungen (abgesehen etwa von Pupillendifferenzen) geblieben. Dagegen war besonders bei einem im Winter 1879/80 zur Section gekommenen Falle der wahre Zusammenhang deutlich nachzuweisen:

Intra vitam waren beide Optici als grał degenerirt diagnosticirt worden, die psychischen symptome waren für die progressive Hirnparalyse characteristisch, die Patellarsehnen-

*) Sehr deutlich tritt in der Epikrise eines nenerdings von Noyes mitgetheilten Falles (acute Myelitis mit doppelseitiger Neuritis optica. Arch. f. Augenheilknnde X. S. 331) hervor, wie die Ophthalmologie noch im Banne der Meinung steht, es könne anch beim aussehliesslichen Vorhandensein rein spinaler Symptome, die zadem im vorliegenden Fall nur auf eine ziemlich weit unten im Rïckenmark sitzende Localisation deuteten, der eigentliche Ursprungsherd der gleichzeitigen Opticuserkrankung nur intracramiell gesucht werden. 
reflexe waren seit mindestens $3 / 4$ Jahren völlig verschwunden. Die Section ergab Leptomeningitis und Rindenatrophie der Convexität beider Hemisphären. Basis frei. Im ganzen Hirn keine Herderkrankung. Hinterstränge des Lendenmarks grau degenerirt. Optici vom ocularen Ende bis über das Chiasma hinaus grau verfärbt, ebenso zeigen beide Olfactorii ein graues atrophisches Aussehen.

Es konnte also hier weder ein centraler Herd, etwa in den Vierhügeln, als Ausgangspunkt für die Optieusatrophie gefunden werden*), noch irgend welche Wahrscheinlichkeit dafü, dass die Frkrankung centrifugal porgeschritten sei, vielmehr lag eine vom ocularen Sehnervenende hirnwärts aufsteigende Degeneration vor, wie sie für spinale Fälle auch von Förster**) angenommen wird. Haben wir nun uns gewiss mit der soeben in der Anmerkung als unmöglich bezeichneten Annahme eines Abhängigkeitsverhältnisses der Opticuserkrankung von der Hirnrinde nicht näher zu beschäftigen, da ja eine secundäre Degeneration nur von einem nächsten Centrum und wenn primär von einem entfermten, so nur durch Fortschreiten der Erkrankung auf das nächste zu Stande kommen kann, ein nächstes Centrum aber für den Opticus ausschliesslich

*) Es muss hier an eine in allerneuester Zeit von Nieden publicirte Krankengeschichte erimnert werden, die eine progressive Paralyse mit Sehnervenatrophie betrifft (Archiv für Augenheilkunde X. S. 622 ff.). Nieden bezieht hier die Opticusaffection auf eine p. mort. constatirte hochgradige Atrophie der Occipitallappen, hat aber gar nicht ans Rückemmark gedacht, das weder intra vitam auf seine Symptome, noch p. mort. untersucht worden zu sein scheint. Es liesse sich bei der ausserordentlich häufigen Coincidenz cerebraler und spinaler Affection beim Paralytiker daranf wetten, dass sie, deren Dirgnose freilich sehr häufig nicht gemacht wird, auch in Niedens Fall vorhanden war, womit auch die Pathogenese der Opticusatrophie klar wird und die absolut unmögliche Annahme fallt, dass eine derartige Rindenerkrankung secundäre Opticusatrophie bewirken kann.

**) Förster, Krankheiten des Nervensystems. Handb. d. ges. Augenheilk. จ. Graefe u. Sümisch Bd. 7. S. 133. 
in basalen Ganglien liegt, die hier ja eben nicht ergriffen sind, so liegt die Sache nun schon einfacher: Wenn der Fall zeigte, dass es eine primäre Affection des Opticusstamms, ohne etwa zu supponirende Erkrankung nächster Centren nach dem Schema der secundären Degeneration, giebt, so redueirt sich das Problem darauf: Ist diese Erkrankung in der Weise abhängig von der spinalen, dass irgend welche, etwa rasomotorische oder trophische, Fernwirkung von einer erkrankten Rückenmarkspartie auf den N. opticus stattfindet, oder handelt es sich um gleichzeitige nicht direct von einander abhängige Localisationen eines krankhaften Processes an verschiedenen Punkten des Nervensystems? Es liegen allerdings a priori noch zwei andere Möglichkeiten vor: Fortleitung durch die Meningen und seit allemeuester Zeit eine Vermittlung durch die von Stilling angegebenen Opticuswurzeln, die schon bis in die Medull. oblong. verfolgt sind. Gegen den meningealen Ursprung, der ja wohl für einige nachher zu erwähnende Fälle acuter zur Heilung gelangter Rückenmarkserkrankung mit Opticusbefund, aber ohne Section, in Anspruch genommen werden könnte, spricht nun einfach in chronischen Spinalaffectionen nicht nur ganz entscheidend der ophthalmoskopische und eventuelle Sectionsbefund, sondern er kann sogar hier schon durch die symptomatische Diagnose (charakteristische Gesichtsfeldeinengung und Farbenstörung) ausgeschlossen werden. Mit der durch die Stilling'seho Angabe eröffneten Perspective, die unter Umständen wohl auch pathologische Bedeutung gewinnen könnte, lässt sich aber doch darum für die uns beschäftigenden Erkrankungen wenig anfangen, weil eben der Continuitätsnachweis fehlt, also für sicher existirende Fälle von gleichzeitiger vorläufig nur auf das Lendenmark beschränkter Spinalaffection and Opticuserkrankung immer noch ein sprungweises Befallenwerden anzunehmen wäre, wofern man überbaupt im Sinne unserer obigen Erklärungen in Wirklichkeit ein direktes 
Abhängigkeitsverhältniss statuirt. Somit würde es sich dann eben auch bei dieser Annahme um eine Fernwirkung handeln, für die dann immerhin ein vasomotorischer oder ähnlich wirkender Mechanismus unserem Verständniss zugånglicher wäre. Wir müssen also jetzt schon, auch ohne die nachher aufzuführenden positiven Thatsachen beizuziehen, behaupten, dass wir mit einer springenden Neuritis, die Opticusfasern im Rückenmark primär beträfe und dann ohne alle Vermittelung und Zwischenstation sich erst wieder an der Papille äusserte, nichts anzufangen wüssten.

Sonach stünden wir in letzter Instanz doch wieder vor dem einfachen Dilemma: gleichzeitiges und unabhängiges Befallensein oder directes Abhängigkeitsverhältniss vom Rückenmark, jedoch die Fernwirkung vermittelt durch einen Apparat, wie er uns beim jetzigen Stand unserer Kenntnisse im vasomotorischen System bekannt ist.

Vorher aber haben wir unsere oben nur mit Bezugnahme auf einen Fall aufgestellte Behauptung, dass in der That ein Tertium non datur und dass speciell die Annahme cerebraler Herde für viele Fälle unmöglich ist, ausführlicher $\mathrm{zu}$ begründen. Den kräftigsten Impuls, unsere Idee weiter zu verfolgen, erhielten wir durch die Falle, die wir in der Literatur über den Zusammenhang von Sehnervenerkrankungen mit Spinalverletzungen auffanden.

Albutt (on the opthalmose. signes of spinal disease Lancet Vol. I. p. 76. 1870 eitirt bei Leber S. 870) fand unter 30 Fällen von ausgesprochener Rückenmarkverletzung 8 Mal Störungen am Auge, jedoch nur bei ehronischem Verlauf, mithin bei weniger sehweren Verletzungen (und zwar 8 Mal unter 13 Fallen).

Mooren (citirt bei Leber 1. c. S. 872) beobachtete einen Fall, wo bei einem Schlag in das Kreuz mit der flachen Hand eine halbstündige Ohnmacht, dann Suhwere der Beine und im weiteren Verlauf progressive Sehnervenatrophie mit Ausgang in Erblindung und andern Spinalerscheinungen anftrat.

v. Grabe's Archiv fir Ophthalmologie, XXVII. 8. 
Vier Fälle von Bruce Claree aus St. Bartholomews Hospital Reports 1880) sind berichtet in The London medical Record 1881 (S. 166 v. 15. April), drei von einfacher Rückenmarkserschütterung, einer von Wirbelfractur. Hier handelte es sich um ,early transient changes in the optic disk. They could not have been even suspected without periodical opthalmose. examination. The appearances noted consisted of hyperamia and sometimes of oedema of the optic disk."

Diesen traumatischen Fallen reihen sich direct die in neuster Zeit publicirten von Neuritis optica bei acuter Myelitis an: die ersten veröffentlichte Erb und Steffan (Bericht der Heidelberger Ophthalmologischen Versammlung rom Jahre 1879), dann folgten Seguin im Journ. of Mental and Nerrous Diseases. Chicago, April 1880, p. 177; Noyes im Arch. f. Augenheilk. X. 3 S. 331, und Rumpf (Deutsche med. Wochensehrift rom 6. August 1881). Besonders auf den letzteren, der für die Theorie der Affection sehr wichtig ist, legen wir grosses Gewicht. Allen gemeinsam ist für das Verständniss ihrer Pathogenese die objectiv klare Sachlage, dass ausschliesslich ein rein spinaler Process vorliegt, wenn auch z. B. Noyes, wie wir schon oben S. 110 Anm. erwähnten, in seinem Erklärungsversuch doch wieder an einen intracraniellen Ursprung zu denken scheint.

Binen Uebergang zu den Opticusaffectionen bei chronischen Spinalkrankheiten bilden Fälle, wo die Erkrankung in ganz acuter Weise einsetzte, später aber in ein chronisches Stadium überging. Aus der Literatur können wir hier nichts besonders Schlagendes beibringen, da die erwähnten heilten und in den Publicationen über fertige Opticusatrophien meist ein neuritischer Beginn gar nicht zugegeben, sondern ein für alle Mal primäre Atrophie angenommen wird, womit sich allerdings ein acuter Beginn schlecht vertruge. Doch erscheinen darum Fälle, wie der von Leber (1. e. S. 819) citirte Hübsch's gerade sehr 
wichtig, wo in offenbar subacuter und darum verfolgbarer Weise, in Begleitung eines doppelseitigen Herpes zoster als Vorläufer von Psychose mit Ausgang in Dementia eine Sehnervenatrophie auftrat."

Wie Leber bemerkt, lässt der Herpes auf eine vorhergegangene Affection der Spinalganglien schliessen und so hätten wir es hier auch mit einem, wenn auch vorderhand ziemlich unklaren spinalen Einfluss zu thun, der eines Tages acut einsetzend als einen seiner Endaffecte Opticusatrophie bedingt. Als analog wären hier einzureihen die Fäle, welche Leber (1. c. S. 946) im Auge hat, wo er mit Bezug auf einen Fall von Hutchinson sagt: "Höchst selten bleibt nach einem Anfall von Amaurosis partialis fugax, der sonst ganz die Charaktere der gutartigen nervösen Erblindungsanfälle zeigt, ein Auge dauernd amaurotisch und es erfolgt Ausgang in Sehnervenatrophie." Hiermit streifen wir schon sehr nahe die pathogenetische Grundfrage, wollen uns aber vorläufig mit der Constatirung der Thatsache begnügen, dass Sehnervenatrophien zuweilen zurückgeführt werden können auf, seien es einmalige, seien es wiederholte, aber doch immer noch den Charakter des Anfallartigen und darum mehr oder weniger Acuten an sich tragende Anlässe. Es fehlen freilich noch genauere Beobachtungen über die allmăhliche Entwickelung aus einem neuritisehen Initialstadium in reine Atrophie, wir werden aber sogleich zeigen, dass wir wenigstens in zweien unserer Fälle im Stande sind, ein anschauliches Bild dieser Entwickelung bei einem rein spinalen Fall zu geben. Auf die Berechtigung, die eben erwähnte Amaurosis partialis fugax hereinzuziehen, werden wir noch zu sprechen kommen und aus der oben angeführten Literatur hätten wir besonders noch der Schilderung des Rumpf'schen Falles Frwähnung zu thun, dessen ophthalmoskopisches Bild nach der Untersuchung von Mooren als, in der Mitte zwischen Neuritis und Stauungs- 
papille stehend", bezeichnet wird. Nun sind aber dieser und die oben mit ihm citirten Fälle zur Heilung gelangt; es würde sich also darum handeln, einerseits einen nicht heilenden lange Zeit hindurch zu verfolgen, andererseits dann an der Hand eines solchen Fälle vollendeter Atrophie, in denen jedoch anamnestisch ein aeuter Beginn mit grosser Wahrscheinlichkeit nachzuweisen ist, in gleicher Weise rïckwärts zu ergänzen.

In ersterer Hinsicht sei nun erwähnt:

1. Eine Patientin, die, obgleich schon mit doppelseitiger Neuritis optica und theilweiser Atrophie behaftet, doch wegen ihrer verhältnissmässig geringen Sehstörungen sich nie in ophthalmologische Behandlung begeben hatte, kam wegen hochgradiger Motilitätsstörungen der Beine in die neuropathologische Behandlung des einen von uns. Sie war ein Jahr, ebe wir sie sahen, im Anschluss an ein Wochenbett und unter dem Einfluss einer starken Erkältung erkrankt. Beschwerden beim Urinlassen, lähmungsartige Schwäche in den Beinen. Die Urinbeschwerden hatten sich wieder verloren, aber der Gang blieb dauernd gehindert. Von sensibeln Störungen ist nur für sie belästigend ein Kältegefühl in Unterschenkeln und Füssen. Die Untersuchung Anfang April 1881 ergiebt völlig intakte Sensibilitätsverhältnisse der unteren Extremitäten, aber sehr hochgradig gesteigerte Patellarsehnenreflexe, zeitweise deutlichen Dorsalclonus, spastischen Gang, keine Spur von Ataxie, Steigerung der Sehnenreflexe auch an den sonst intakten. Oberextremitäten. Kopf völlig frei. Pupillen normal. Nach dem Sehvermögen befragt, giebt sie an, dass ihre Augen seit Beginn ihrer Erkrankung schwächer geworden seien.

Ophthalmologische Untersuchung:

16. April 1881: Bds. E. Rs. Finger in 5, Ls, in $6 \mathrm{~m}$. Sn. $D=2,25$ für die Năhe. Gesichtsfeldgrenzen, Farbenempfindung normal. verfärbt.

R. opticus im inneren obern Quadranten etwas grau

25. April. Funetionen gleich. Heute erscheint $R$, auch der innere untere Quadrant der Papille dentlich verfärbt, so dass die ganze temporale Hälfte leicht grangrün und transparent erscheint. 
Auf dem L. Auge ist in der temporalen Hälfte der Papille entschieden eine stärkere Transparenz als normal und zugleich eine graue Verfärbung mit ziemlich dunkler Nuance vorhanden.

16. Juni. Erneute Untersuchung, bei der sich nun findet, dass beiderseits neuritische Erscheinungen in der medialen Hälfte der Papille in Vordergrund getreten sind. Es besteht eine sehr starke capilläre Hyperaemie mit leichter Schwellung des Sehnervengewebes, während in der temporalen noch die atrophische Färbung fortbesteht. Auch zeigen die Gefässe streckenweise eine Verbreiterung ihres Durchmessers, besonders die Venen. Die Functionen waren im Wesentlichen die gleichen geblieben, abgesehen von einem bemerkenswerthen später zu schildernden Verhalten der Farbenperception.

Dieses Gemisch von neuritischem und atrophischem Bild präsentirte sich auch noch bei einer am 6 . Juli wiederholten Untersuchung.

2. Ein Patient*) wurde im Jahre 1878 plötzlich beim Verlassen des Zimmers bewusstlos und war damals angeblich 11 Wochen lang an beiden unteren Extremitäten gelähmt. Bei dem Anfall soll rom Arzt constatirt worden sein, dass die Haut auf der ganzen rechten Körperhälfte stark geröthet war. Nach dem Zurückgehen der Lähmung blieben periodisch auftretende epileptische Anfälle, cardiale Beschwerden und das hänfig anftretende Gefïhl von Hitze und Kälte im Gesicht und den Füssen lange Zeit zurück. Patient darauf arbeitsfähig, erkrankte wieder im Sommer 1880 unter gastralgischen Symptomen. Paraesthesien. Langsam eintretende Klauenstellang der Zehen und Finger, Schmerzhaftigkeit der Wirbelsäule. Urinentlerung erschwert. Patient hat als G]ockengiesser viel am Feuer gearbeitet. Keine neuropathische Belastung; seit kurzer Zeit Verschleierung des Gesichtes.

St. Ausgesprochen spastischer Gang besonders des rechten Beines. Patellarsehnenreflexe enorm gesteigert. Dorsalklonus nicht nachzuweisen. Die Sensibilität des rechten Beines nur für ganz feine Berührungen gestört, Leitung prompt. Hautreflex normal; die grobe Kraft rechts bedeutend herabgesetzt, Starke Schmerzhaftigkeit der Wirbelsäule bei Druck auf die

*) Die Aufnahme dieses Falles in unserer Arbeit verdanken wir der Güte des Herrn Dr. G. Merkel, Kgl. Bezirksarzt und Oberarzt am städtischen Krankenhans in Nïrmberg. 
Spinalfortsätze der Brustwirbel, die leise Berührung der Haut mit dern Finger hinterlässt schon eine anbaltende Röthe, besonders an der rechten Körperhälfte. Keine Lues.

R. A. H. $2.0 \mathrm{D}$. F. in $3 \mathrm{M}$.

L. A. K. 2.0 D. $S=\frac{1}{3}$.

Pupille beiderseits $3 \mathrm{~mm}$ weit, prompt reagirend. Farbenperception nicht gestört.

Ophthalmoskopisch. Beide Optici sehr stark capillär injicirt, besonders rechts. Die Papille etwas trübe, die Conturen wenig verwaschen. Das ganze Gefässsystem der Retina abnorm stark gefüllt, rechts die Venen hochgradig gestaut und eine unregelmässige Füllung der Blutsäule sehr deutlich in der Weise ansgesprochen, dass die renösen Gefässe die verschiedenste Breite im Durchmesser besitzen und die breiten Stellen zugleich eine dunklere Farbe der Blutsänle aufweisen. Das Spiegelbild weehselt bei hänfiger Untersuchung während einiger Wochen häufig in der Weise, dass die capilläre Hyperaemie des Sehnerven wie die Füllungszustände der gröberen Gefässe bald sehr stark, bald nur sehr gering ausgesprochen sind. Bei der Untersuchung wird Patient regelmässig durch den Lichteinfall so irritirt, dass eine sehr bedeutende Thränensecretion eintritt and er über starke Beschwerden klagt.

Drittens haben wir hier auzufügen einen Paralytiker der Irrenabtheilung mit gesteigerten Patellarreftexen und Dorsalclonus, sowie den unten zu sohildernden spinalen Pupillenphänomenen. Am 7. Juni 1881 ist ron ihm notirt: Ls. Opticus normal, Rs. die nasale Hälfte stark hyperämisch. Contur verwischt, leichte Schwellung. 14. Juli: Ls. frische Neuritis, Rs. Befund nicht sehr verschieden von der ersten Untersuchung, jedoch macht sich schon das Bild der Atrophie durch weissliche Verfärbung des Opticus geltend.

Wenn uns aus diesen Fällen hauptsächlich das Zusammenvorkommen neuritischer und atrophiseher Processe tund ihr Uebergang in einander interessirte, so haben wir noch einmal mit besonderem Nachdruck auf den Rumpf'schen Fall zu verweisen, in dem zwar keine Atrophie zu Stande kam, wohl aber das acut entstandene Bild ein derartiges war, wie es, falls es nicht zur Norm zurück- 
kebrt, stets in das der Atrophie zu endigen pflegt. Ein derartiger Ausgang ist darum auch bei obigen Fällen mit ziemlicher Sicherheit zu erwarten, wobei eben der Unterschied von den geheilten acuten Fällen darin liegt, dass hier die Natur des Grundleidens einen schleichenden progressiven Charakter bedingt. Ebendamit hängt aber auch der weitere wichtige Umstand zusammen, der bei einer epikritischen Vergleichung unserer Fälle mit denen der Literatur von acuten Erkrankungen sehr ins Gewicht fallen muss, dass solche schleichende neuritische Processe offenbar so wenig Sehstörungen verursachen, dass die Patienten nicht zum Augenarzt kommen. Vollends ein Paralytiker beklagt sich nie über Abnahme der Sehschärfe und es wird deshalb orst ein grosses Beweismaterial erbracht werden können, wenn jeder Rückenmarkskranke in der Nervenklinik, in der Irrenanstalt, in der Privatpraxis opthalmoskopirt, und jede hierhergehörige Opticuserkrankung in der Augenklinik sachgemäss auf spinale Symptome untersucht wird.

Nun scheint freilich in einer beträchtlichen Zahl von Fällen eine erhebliche Abnahme der Sehfunctionen auch bei genauester Anamnese erst allerjüngsten Datums und trotzdem ergiebt die Untersuchung schon das vollendete Bild der Atrophie. Hierdurch hat sich wohl die Ueberzeugung noch mehr befestigt, dass die Atrophie stets eine primäre sei. Thr neigt sich im Ganzen auch Leber zu, der auch den Satz ausspricht, dass bei tabetischer Atrophie hyperämische Zustände nie beobachtet werden. (1. c. S. 871.) Es liesse sich nun vielleicht discutiren, ob eine primäre Atrophie eines bisher gesunden Sehnerven überhaupt im Einklang mit unsern sonstigen Kenntnissen ron Nervenerkrankangen $\mathrm{zu}$ bringen ist, allein da wir für unser Gebiet zwar nunmehr beweisen können, dass der in Atrophie endende Process auf neuritischem Wege zu Stande kommen kann, keineswegs aber strikte, dass er es immer 
muss, was wir höchstens wahrscheinlich machen und ferneren Beobachtungen überlassen können, so wollen wir uns mit der Statuirung des ersteren Factums vorderhand begnügen. Es ist aber jedenfalls erwähnenswerth, dass Leber selbst vermuthungsweise davon spricht, es könnte dem Rückenmark ,ein directerer Einfluss auf die Ernährung des Sehnerven zukommen" and es könne derselbe auch dem Auftreten der Sehnervenatrophie bei Tabes dors. zu Grunde liegen. Wenn es uns gelungen sein wird, die Natur dieses Zusammenhangs aufzudecken und dass derselbe auf die Regulirung der Circulation im Augenhintergrund durch das Rückenmark zurückzuführen ist, so wird eben dadurch auch der neuritische Beginn wahrscheinlicher, der aber nur selten gesehen wird, weil die Functionsstörungen noch sehr unerheblich sind. Der durch Leber von ophthalmologischer Seite ausgesprochenen Vermuthung eines solchen directen Abhängigkeitsverhältnisses steht übrigens, wie gleich hier bemerkt werden mag, ein ganz analoger Satz des Neuropathologen Erb zur Seite: „Auch der nicht fernliegende Gedanke, dass die Erkrankung der Hinterstränge des Rückenmarks trophische Einwirkungen anf die Optici entfessele und so die graue Degeneration derselben bedinge, kann wohl nicht festgehalten werden angesiohts der Thatsache, dass die Sehnervenatrophie oft sehr lange Zeit allen Erscheinungen der spinalen Erkrankung vorausgeht." (Erb, Krankheiten des Rückenmarks. 2. Aufl. 8. 589.) Dies datirt vom Jahre 1878. Heute, wo wir gerade, Dank den von Erb entdeckten Sehnenreflexen seither immer mebr Fälle kennen gelernt haben, die ohne dieses diagnostische Hülfsmittel noch absolut nicht als spinal erkrankt erkannt werden konnten, dürfte wohl dieses Bedenken viel weniger schwer wiegen, zumal da wir in einer Reihe von Fällen eben hauptsächlich durch die fehlenden Sehnenreflexe unsere Opticusatrophieen als schon gleichzeitig spinal erkrankt diagnosticiren konnten, und so 
dürfte auch der resignirte Schlusssatz Erb's: „Es bleibt aber vorläufig nicht viel Besseres übrig als der Schluss, dass sich die graue Degeneration ,gleichzeitig oder successive an verschiedenen hierzu besonders disponirten Punkten des centralen Nervensystems entwickelt" (Förster)" der Ueberzeugung von der Möglichkeit der Erkenntniss eines klaren Mechanismus Platz machen. Die eben angeführte Förster'sche Auffassung war auch die A. v. Graefe's gewesen (cfr. Leber 1. c. S. 871) und wir haben sie ja oben auch als die eine der beiden möglichen gleichwerthig angeführt, es dürfte aber als Wahrscheinlichkeitsgrund gegen sie schon die Erwägung in die Wagschale fallen, dass bei den rein und sicher idiopathisehen Erkrankungen des inneren Auges Erkältungen einen eigentlich absolut gleich Null zu setzenden Factor bilden, bei den mit spinalen Symptomen verknüpften diese aber nachweislich häufig eine nicht zu unterschätzende Rolle spielen. Nimmt man nun ferner die oben aufgeführten traumatischen Fälle hinzu, in denen das Abhängigkeitsverhältniss vernünftigerweise nicht geleugnet werden kann, so darf nun allerdings nicht stricte gefolgert werden, dass es sich nun in allen Fallen um den gleichen Mechanismus handeln müsse, immerhin hat aber die Annahme, nun da einmal festgestellt ist, dass der gleiche Effect auf diesem Wege zu Stande kommen kann, für das Bestreben nach einheitlichem Verständniss viel Verlockendes. Und um noch die oben angedeuteten Fälle hier nachzutragen, in denen die erwähnte zweite Möglichkeit der Reconstruction eines acuten Beginns auch einem ausgesprochen und ausschliesslich atrophischen Bild gegenüber sich eröfnet, so ergiebt sich ja für sie ebenso die grosse Wahrscheinlichkeit, dass jener acute Beginn in einer neuritischen Form bestand, als sie sich denen anreihen, für welche die Annabme einer gleichzeitigen aber unabhängigen Localisation 
in Sehnerv und Rückenmark etwas höchst gezwungenes hätte. Es sind folgende:

1. A. M., Eisengiesser, 36 Jahre, rec. 7. Mai 1881. Keine hereditäre neuropathische Disposition. Vater zur Zeit der Zengung beinahe 60 Jahre alt, 30 Jahre älter als die Mutter. Als Kind Masern, geschwollene Halsdrüsen. Später gesund, kräftig. Als Soldat im Feldzug luetisch inficirt. Condylome. Vom 25. Jahre an bis vor zwei Jahren andauernd als Eisengiesser beschäftigt, stets der Gluthhitze ausgesetzt. Sommer 1879 starke Erkältung, lehnt sich überhitzt mit nacktem Oberkörper an einen Steinblock, darauf heftiges Frösteln, zwei Tage darauf Nebel vor den Augen, Müdigkeit in den Beinen. Nach zwei Monaten häufiger Urindrang mit Schmerzen, der nach 4-5 Monaten wieder verschwunden ist. Sehvermögen progressiv schlechter, sonst restirten nur Müdigkeit in den Beinen, zeitweise leichtes Gürtelgefahl. Kommt in die Angenklinik wegen zunehmender Sehschwäche, seit längerer Zeit deswegen arbeitsunfähig.

Stat. rec.: L. A. E. $S=\frac{1}{10}$. R. A. E. Finger in $1,5 \mathrm{~m}$.

Gesiehtsfeld: Auf beiden Augen fanden sich in dem im Ganzen concentrisch-eingeengten Gesichtsfeld noch eine Reihe von sectorenförmigen Ausschnitten, so dass sich das Gesichtsfeld besonders charakteristisch am rechten Auge in folgender Weise abgrenzt (Förster'sches Schema): 0-180 40 nach oben aussen, resp. unten innen, 20-160 40 48, 40-140 50, $60-1203540,80-1005250,90-906550$ nach aussen unten, resp. innen oben, $100-805245,120-604540$, 140-140 50 45, 160-20 52 40. Farbenperception normal. Augenmuskeln intact. Opticus beiderseits graweiss. Ris. u. Ls. d ünne Arterien, leichte venöse Stanung. Geruch beiderseits bedeutend herabgesetzt, was Patient spontan schon angiebt. Hörweite, Geschmack normal.

Pupille beiderseits auf Lichteinfall reagirend, aber auffallend träge, $3 \mathrm{~mm}$ weit. Keine Reaction auf schmerzhafte Hautreizung mit faradischem Pinsel, prompte Verengerung bei Convergenzbewegungen.

Bauchhautreflexe sehr lebhaft. Schon auf leise Berährung der Haut des Rumpfes und Bauches starke reflectorische Zuckungen, die bei Verstärkung des Reizes auf 
sämmtliche Extremitäten irradiiren. Cremasterreflexe normal. Patellarsehnenreflexe fehlen vollständig. Die Dorsalflexion des Fusses auszuführen gelingt beiderseits nicht wegen enormer Hyperästhesie der Fusssohlen, die bei der leichtesten Berührung ein convulsivisches Zurückziehen des Beins zur Folge hat. Schmerzempfindung für Nadelstiche Rs. im Bereich der Wadengegend und des Fussrückens herabgesetzt. In diesem Bezirk auch Entscheidung für Nadelspitze oder Knopf häufiger falsch als Ls. Im R. Fuss giebt Patient ein permanentes deutliches Gefühl von Kälte an, objectiv kein Temperaturunterschied zu constatiren. Im. Bereich der erwähnten Zone verminderter Schmerzempfindung Rs. schlechtere Unterscheidung zwischen warm und kalt.

2. P. B., 47 Jahre, Gärtner, rec. 10. Juli 1881. Aus gesunder Familie. Seit 17 Jahren verheirathet. Nie luetisch, Vater gesunder Kinder. Patient früher immer gesund, hatte zuerst im Sommer 1880 abnormen Urin- und Stuhldrang, sowie zeitweise blitzartige Schmerzen in den Beinen. Im Februar 1881 erkältete sich Patient bei Hochwasser durch langes Stehen im kalten Wasser während 5 Stunden. Am Abend nach diesem Tag beim Lesen der Zeitung plötzliche Verschleierung der Augen. Die andern Beschwerden, Stuhldrang etc. kehrten nie mehr wieder, wohl aber in newerer Zeit abnorme Müdigkeit in den Beinen. Das Sehvermögen nahm fortschreitend $a b$.

Die Unmöglichkeit, Farben zu erkennen, bemerkte Patient plötzlich einen Monat nach dem ersten Auftreten der Sehstörung.

Stat. rec.: Patellarsehnenreflexe beiderseits vollständig fehlend. Hörweite Rs. auf $2 \mathrm{~cm}$ herabgesetzt. Sonst alles normal.

R. A.: Finger in $23 / 4 \mathrm{~m}, \mathrm{~L}$. in $6 \mathrm{~m}$. Mit Gläsern keine Besserung. Gesichtsfeld: Beiderseits in der Peripherie beginnende sectorenförmige Einschränkung.

Farbenperception: Grün-Rothempfindung vollständig. fehlend; Blau-Gelb in den hellsten Nuancen noch theilweise, aber unbestimmt unterschieden und zwar bei intensiver Beleuchtung, am besten Morgens.

Pupillen beiderseits $3 \mathrm{~mm}$, starr ohne jede Reaction auf Lichteinfall, Convergenzreaction erhalten.

Optici beiderseits von ausgesprochen grau-weisser Farbe. Erhöhte Transparenz des Gewebes, der R. Opticus ohne jede 
Nuance von Roth. Conturen scharf. Lamina cribrosa mässig eingesunken. Ls. in der temporalen Hälfte noch ganz leichter, röthlicher Farbenton. Die Conturen etwas unregelmässig, in der temporalen Hälfte ganz leicht verschwommen. Venen beiderseits etwas breiter als gewöhnlich. Arterien eher enge, schlecht gefüllt.

3. M. B., 61 Jahre, Bauer, rec. 6. Juli 1881. Patient ans gesunder Familie, seit seiner Jugend auf dem rechten $\mathrm{Ohr}$ schwerhörig, das linke wurde 6 Wochen nach Beginn seines jetzigen Leidens schwächer. Nie luetisch inficirt. In August 1879 arbeitete Patient eines Abends auf dem Feld und gerieth dabei in heftigen Schweiss; ein stärkerer Luftzug verursachte alsbald ein unangenehmes Kältegefühl und Schaudern, er machte sich hieraus nicht viel, sondern setzte sein Geschäft fort. Plötzlich wurde es dunkel vor seinen Augen, so dass er glaubte, die Nacht breche herein, und die mit ihm Arbeitenden aufforderte, nach Hause zn gehen, wegen des Eintritts der Dämmerung. Die Verschleierung des Gesichtsfeldes hielt an und das Sehvermögen wurde in wenigen Tagen so schlecht wie es heute noch ist.

Stat. ree. Der Allgemeinbefund ist ganz negativ, abgesehen von höchst interessanten vasomotorischen Störungen, die unten (Seite 127) gesehildert werden sollen.

Rs. A.: Finger in $3 / 4$, Ls. jn $1 / 4 \mathrm{~m}$.

Gesichtsfeld nicht aufzunehmen, da Patient zu schlecht fixirt. Farbensinn normal. Pupille $4 \mathrm{~mm}$ weit, reagirt normal. Der Augenspiegel ergiebt die Papille links wie rechts granweiss, von erhöhter Transparenz. Gefässe beiderseits ziemlich eng.

Es war in der ganzen bisherigen Beweisführung ausschliesslich nur vom Optious die Rede; es ist jetzt noch darauf hinzuweisen, dass die Annahme der blossen Gleichzeitigkeit durch die beiden andern spinalen Augensymptome, Augenmuskellähmungen und spinale Myosis resp. Pupillenstarre auch durchaus keine Stütze erhält. Wir werden im Stande sein, nachzuweisen, dass auch für sie die Annahme gleichzeitiger intracranieller Herde nicht nur für alle Fälle überflüssig, sondern auch für viele direkt den Thatsachen zowiderlaufend ist - und wenn dann auch 
hier die spinalen Erkrankungsherde als die einzigen anatomischen Localisationen stehen bleiben, so ist alsdann völlig klar, dass es sich hier nur um ein directes $\mathrm{Ab}$ hängigkeitsverhältniss handeln kann, da ja doch die Annahme, dass etwa Nervenzweige für die Pupille oder Augenmuskeln primär erkranken, sicher ausgeschlossen sein wird. Für eine unbefangene Beobachtung brauchte übrigens die Thatsache der Abhängigkeit kaum mehr besonderer Beweise, da die Häufigkeit der Coincidenz eine so grosse ist, dass eine Unabhängigkeit der Krankheitslocalisationen von einander doch nur dann angenommen werden dürfte, wenn wirklich irgend welcher Anhaltspunkt dafür vorläge, dass gerade immer die beiden räumlich weit getrennten Stellen des Nervensystems Prädilectionsstellen bildeten. Es kann freilich hiergegen eingewendet. werden, dass wir anch für die gleichzeitige Localisation des Krankheitsprocesses an der Rinde der Convexität und in den Hinter- und Seitensträngen des Rückenmarks, wie sie eine so häufige Combination bildet, kein sicheres Verständniss besitzen, da sie nach dem Schema der absteigenden Degeneration aufzufassen bei mangelndem Continuitätsnachweis nicht erlaubt ist. Ein auf diese Analogie sich stützender Einwand gegen das Abhängigkeitsverhältniss wird allerdings blossen Wahrscheinlichkeitsgründen für dasselbe gegenüber immer Werth behalten und die Nothwendigkeit directer Beweise darthun. Es muss aber doch hier der Vollständigkeit halber noch eine Classe von Fällen beigezogen werden, die zwar auch nur Analogieschlüsse gestatten, die aber bei ihrer späteren genaueren Beschreibung sich für uns wichtig erweisen werden: wir meinen die von weiblichen Sexualkrankheiten abbängigen Opticusaffectionen, über die Mooren ganz neuerdings eine höehst belehrende Arbeit veröffentlicht hat (Archiv f. Augenheilkunde X. S. 519 ff.). Das Wesentliche für uns an diesen Fällen ist vorderhand das hier direct nachweisbare Abhängigkeits- 
verhältniss von Erkrankungen entfernter Organe. Wenn diese für gewönlich und in den weitaus überwiegenden Fällen nur Cireulationsstörungen im Augenhintergrunde setzen, so führen sie doch auch zuweilen zu degenerativen Processen, ein Punkt, der für uns später erst von höchster Wichtigkeit werden wird. Dass wir aber berechtigt sind, bei der Betrachtung der spinalen Einflüsse anch an sie zu. denken, dafür möge die ron Mooren bestimmt angedeutete Thatsache sprechen, dass Myelitis häufig die Vermittlung zwischen Genitalleiden und Opticusaffection bildet. Freilich kommt er dabei auf die chronischen Spinalleiden nicht zu sprechen, trotzdem ist der Weg, um den es sich für uns handelt, deutlich bezeichnet und ich möchte besonders noch den ganz treffenden Satz (1. c. S. 55) hervorheben: „Es ist ebensogut möglich, dass die durch die erwähnten Nervenverbindungen eingeleitete Reizvermittlung direct auf den Opticus übertragen wird und gewissermassen nur als Entzündung in dem Endglied der Leitungsbahn zum Ausdruck gelangt, während das Rückenmark als solches keinen Augenblick hierdurch irgend eine Spur des Erkrankens darbietet."

Dass aber der Weg durch das Rückenmark führt, ist hierin deutlich ausgesprochen.

Können wir nun einen Mechanismus nachweisen, der für die Pathogenese unserer Fälle verwerthbar ist? Die Vermuthung, dass es ein vasomotorischer sein möge, wurde uns zuerst durch die Beobachtung unserer oben beschriebenen Fälle nahe gelegt. Dass dieselbe nicht neu ist, ersehen wir sofort aus folgender Stelle bei Leber (l. c. S. 871): „Da an einen directen Einfluss des Rückenmarks auf das Sehvermögen nicht gedacht werden kann, so hat man vielfach vasomotorische Störungen als Mittelglied angenommen. Es ist dafur die Beobachtung von Wharton Jones (On the occurrence of amaurot. amblyopie long after the injury in cases of concussion of the spinal 
marrow. Brit. med. Journ. Juli 2. H. 1869) von grosser Bedeutung, dass auch nach Spinalverletzungen und zwar Jahre lang nachher zuweilen Amaurose auftritt." Sie wäre also nach dem oben Angeführten den Rückenmarkstraumen anzureihen, gleich aber hinzuzufügen, dass die Erklärung Wharton Jones" völlig abweicht von der des oben angeführten Albutt. Während dieser eine nach oben sich fortpflanzende Meningitis annahm, glaubt Wharton Jones, dass die Erkrankung des Sehnerven bei Spinalleiden überhaupt durch eine Affection des Sympathicus hervorgerufen werde (cfr. Leber 1. c. S. 871) „durch Lähmung der vasomotorisehen Nerven sollte es zuerst zu einem hyperämischen Zustande und später zur Atrophie der Sehnerven kommen." Indem wir vor dem Ausdruck "Affection des Sympathicus" warnen und höchstens eine in der Bahn des Sympathicus verlaufende Störung zulassen möchten, acceptiren wir doch vollständig die Richtigkeit des von Wharton Jones, dem allem nach die Priorität zu gebühren scheint, ausgesprochenen Gedankens. Was seiner allgemeinen Annahme hindernd im Wege stand und was z. B. gleich Leber ihm entgegenstellte, dasss bei chronischen Rückenmarkskranken eben ein solches Initialstadium nicht beobachtet wird, davon haben wir schon oben gesprochen.

Wir trachteten nun schon lange darnach, einmal einen klinischen Fall in Beobachtung zu bekommen, in dem neben der Opticuserkrankung dieses vasomotorische Element eine recht deutliche Rolle anch auf andern benachbarten Bahnen spielen würde. Ein solches bot sich nun in erwünschtester Weise in dem oben angeführten (S. 124), dessen Beobachtung ich in dieser Richtung hier weiter ergänze:

Der betreffende Patient machte spontan die Angabe, dass er seit jenem Tage, an dem die plötzliche Verschlechterung seines Sehvermögens eingetreten war, sehr häufig ein Gefühl 
von Hitze in den Ohren und im Kopf, heisse Wangen, Ziehen und Reissen im Nacken habe, sowie ein Gefühl von Schwere in den Ohren, als ob etwas daran hänge und ebenso ein Gefühl von Geschwollensein in Kinn und Wangen, ausserdem hätten ihn seine Angehörigen häufig darauf aufmerlssam gemacht, dass seine Augen gegen früher starls geröthet seien; im Ganzen meinte er, "sein Kopf und Hirn seien ganz glïhend geworden." In der That sind auch Erscheinungen starker Hyperaemie an Kopf und Gesicht während des mehrwöchigen Aufenthalts in der Klinik häufig objectiv zu constatiren gewesen.

Ein noch viel schlagenderer Fall dieser Kategorie ist aber folgender:

Eine 30jährige Patientin präsentirt sich in der Angenklinik wegen Abnahme des Sehvermögens. Die ophthalmoskopische Untersuchung ergiebt starke Verbreiterung und Schlangelung der Arterien; auf einem Auge ausserdem eine leichte eapilläre Hyperämie und Schwellung der Papille, dabei war das von Hause aus stark neuropathisch disponirte Individunm mit einer weichen doppelseitigen Struma behaftet, von der sie ausdrücklich angab, dass sie zeitweise bedentend anschwelle. Pulsfrequenz von 120-130 mit bedeutender Arythmie. Das Gesicht der Kranken überzieht sieh beim geringsten Anlass mit einer Purpurröthe einschliesslich der Ohren, und darauf beziehen sich auch die Hauptklagen der Patientin, die von einem fortwährenden Gefühl von Hitze im Kopf gequält wird. Dieser Zustand besteht schon über ein Jahr und sie gibt an, sie sei schon im vorigen Winter dermassen davon gequält gewesen, dass sie sich hüten musste, einem heissen Ofen auch nur nahe zu kommen, weil sie davon jedesmal stundenlang flammenrothe Ohren davongetragen habe, dabei war aber nie eine Spur einer Exophthalmus vorhanden und fehlt auch jetzt das v. Graefe'sche Symptom vollständig.

Fehlen der Mitbewegung des obern Lids.

Gesichtsfeld and Farbenperception normal.

Beiderseits $\mathrm{E} \mathrm{S}=\frac{2}{3}$.

Gewinnen aber so in der That vasomotorische Störungen erhöhte Bedeutung, so musste sich doch sofort der 
schwerwiegende Einwand erheben, dass diejenigen Affectionen am Auge, die nachgewiesenermassen auf vasomotorischen Störungen beruhen, wohl sichtbare Verändernngen am Augenhintergrund bedingen, nicht aber zu entzündlichen oder atrophischen Erscheinungen daselbst zu führen pflegen. In erster Linie musste es sich dabei um den Morbus Basedowi, sowie um die mechanischen Läsionen des Halssympathicus handeln. Wir wurden dadureh veranlasst, das Material der Klinik aus den letzten Jahren auf Sympathicusaffectionen anzusehen. Bekannt war der charakterische Symptomencomplex: Ptosis, Myosis, Erweiterung der Gefässe des betr. Augenhintergrundes und Herabsetzung des intraocularen Druckes. Wir konnten diesen Befund in sechs Fällen bestätigen, bei denen es sich in dreien um den Druck einer hochgradigen Stroma handelte, in einem tiefgreifende syphilitische Affectionen am Hals als mechanisches Causalmoment zu Grunde lagen, während in zwei Fällen ein solches nicht nachweisbar und dieselben in die unbestimmte Kategorie idiopathischer Sympathicusstörungen eingereiht werden mussten, wofür als Erklärung nur die überhaupt stark neuropathische Natur der beiden weiblichen Individuen, von denen die eine geisteskrank war, in Anspruch genommen werden konnte.

In einem weiteren Fall von mechanischer Compression durch einen grossen Kropf konnten wir ein ganz abweichendes und darum erhöhtes Interesse bietendes Verhalten beobachten:

Eine Patientin, 41 Jahre alt, stammt ans einer Kropfgegend, hat seit ihrem 13. Jahre eine starke nur rechtsseitige harte Struma. Yit 15 Jahren "Rothlauf”, das sich ausschliesslich auf die rechte Gesichtshälfte besehränkte. Das Gesicht war dabei sehr stark geschwollen und die Geschwulst demarkirte sich auf stirn und Nasenrücken vollständig in der Mittellinie. Diese Affection wiederhalte sich noch $3 \mathrm{mal}$, nach v. Graefe's Archiv für Ophthaimologie, XXVII, 3. 
jedesmal mehrjährigen Zwischenräumen, das letzte Mal vor zwei Jahren, wobei besonders auch jedesmal das rechte ohr stark geschwollen war. Patientin kommt non in die Augenklinik, weil in neuester Zeit Schmerzen im rechten Auge anfgetreten sind. Die Untersuchung ergiebt:

Die Haut der rechten Wange ist besetzt mit einer grossen Anzahl an der Schläfo und dem aufsteigenden Unterkieferast sich begrenzender blan-röthlicher livider Flecke, die in unregelmässigen Figuren mit einander in Verbindung stehend, inselförmig ausgebreitet sind. Einzelne dieser Flecke sind leicht in die Haut eingesunken und etwas weisslich glänzend, während die andern, vollständig im Niveau der Haut liegend, die geschilderte Farbe zeigen. Das rechte Ohr ist stark geröthet, das Ohrläppchen gegenüber dem linken etwas gedunsen. Temperatur local rechts erböht gegen links. Suprainfraorbitaler and inframaxillarer Schmerzpunkt sehr empfindlich. Das Sehvermögen auf dem rechten Auge auf quantitative Lichtempfindung reducirt; periphere Perception gut. Enge vordere Kammer, diffuse Drucktrübung der Hornhant, enge Pupille mit vollkommen adhärentem Rande und leichten Exsudatschwarten; steinharter Bulbus.

Die ophthalmoskopische Untersuchung wegen der Trübung der Medien unmöglich.

Wir haben diesen Fall deshalb so ausführlich mitgetheilt, weil er zeigt, wie eingreifende Folgen eine rein mechanische Beeinträchtigung des Halssympathicus haben kann. Denn nur um eine solche konnte es sich ja doch füglich bei der sonst ganz gesunden und nur mit einseitigem hartem Kropf behafteten Person handeln. Da der Halssympathicus in der von uns anternommenen Aufhellung des Mechanismus der spinalen Augenaffectionen sich als eine sehr wichtige, wenn vielleicht auch nicht aussehliessliche Bahn ergeben wird, so wird es gut sein, wenn wir hier schon näher eingehen auch auf die pathologisehen Effecte, die aus Störungen eben dieser Bahn in ihrem Verlauf resultiren können.

Zuvörderst können wir an einem Fall unserer Beobachtung den Sympathicus gewissermassen bis zum Rücken- 
mark verfolgen in einer Weise, die völlig im Einklang steht mit der Auffassung, die ihn im Wesentlichen als einen Spinalnerven betrachtet.

Es handelt sich nämlich ebenfalls um das typische Bild der Sympathicusaffection mit den angegebenen zwei Augensymptomen, jedoch mit der bemerkenswerthen Eigenthümlichkeit, dass während in jenen Fällen entweder im Gesichte keine vasomotorischen Störungen bemerkbar waren (in zwei Fällen) oder wenn (in den übrigen 4), dann auf der gleichen Seite mit dem afficirten Auge, hier die Affection in der Weise gekreuzt war, dass das linke Auge und die rechte Wange betroffen erschien. Das betreffende weibliche Individuum starnmt ans taberculöser Familie, litt in der Kindheit an Drüsenschwellungen und nun seit vier Jahren an einer tubereulösen Spondylitis in der Gegend der untersten Brustwirbel. Ungefähr seit derselben Zeit leidet sie an Anfällen von Herzklopfen und dabei wird dann jedesmal die rechte Gesichtshälfte beiss und roth und producirt reichlich Schweiss. Dagegen besteht permanent links Ptosis, Myosis, T. - 2, Erweiterung der Retinalgefässe. Die Halsdrüsen normal. Hier lag nun gar kein anderes Causalmoment vor als die Wirbelerkrankung. Die Symptome, die dieselbe für die untern Extremitäten setzte, waren derart, dass eine tiefergreifende Rückenmarksläsion auszuschliessen und im Ganzen nur eine Compression austretender Nervenstämme zu diagnosticiren war (sog. Symptomes extrinsèques von Charcot); in dieser Weise war num auch die, auf einen Ramus communicans des Sympathicus wirkende Schädlichlreit zu erklären. Was das merkwürdige gekreuzte Verhalten der Störung im Gesicht betrifft, so werden wir bald analoge experimentelle Daten beizubringen haben.

Nun haben wir zwar in den vorstehenden Fällen von Läsionen im Verlauf des Sympathicus Hyperämie des Augenhintergrundes constatiren können, für Entstehung 
eigentlich entzündlicher oder gar atrophischer Vorgänge auf diesem Wege fehlt uns aber noch jeder Anhaltspunkt und ebenso scheint auch der ebenfalls hierher gehörige Morbus Basedowi, soweit Fälle aus der Literatur bekannt sind, keinen zn bieten, an den sich in dieser Richtung anknüpfen liesse. Einmal trat uns aber hier ein Befund entgegen, der in dieser Hinsicht grosses Interesse bot.

Es handelte sich um eine seit 12 Jahren erkrankte Patientin mit starker doppelseitiger Struma, doppelseitigem Exophthalmus, ausgeprägten kardialen Symptomen. Bisher, ohne durch ihre Leiden arbeitsunfähig gemacht zu sein, als Dienstmädchen beschäftigt, trat sie auf die Abtheilung für Hantkranke wegen eines Erythema nodosum, dessen Zusammenhang mit der Grundkrankheit anf der Hand lag. Während wir nun hier den Becker'schen Capillarpuls suchten, fanden wir denselben nur sehr gering ausgeprägt, dagegen beide Papillen in ihrer temporalen Hälfte leicht geschwellt, wenig transparent, Capillarnetz stark gefüllt und die Contur völlig verwaschen. Die peripapilläre Zone der Retina nicht weiter verändert. Die Diagnose musste auf eine mässige Papillitis der temporalen Hälfte gestellt werden. Anhaltspunkte für die Annahme einer sonstigen intracraniellen oder spinalen Erkrankung lagen durchaus nicht vor. Es konnte sich also hior um die Entscheidnng darüber handeln, ob dieser, ophthalmoskopische Befund und die Basedow'schen Symptome ohne directe Abhängigkeit des ersteren von diesen anf eine Hirnerkrankung als gemeinsame Ursache bezogen werden müssen, etwa in dem Sinne dor Filehne'schen Experimente über Erzeugung Basedowscher Symptome durch Läsion ron Vagusbahnen in den Corpora restiformia oder ähnliche - dass es sich also hier z. B. um einen Tumor in betreffenden Regionen handelte. Oder aber wäre bei Ausschluss dieser Möglichkeit wohl nur die Annahme einer durch die langjährig bestehende Circulationsstörung secundär verursachten Neuritis geblieben. Die Entscheidung in ersterem Sinne ist selbstverständlich sehr ersehwert durch das Fehlen jeglichen sonstigen sie unterstützenden Symptoms, zumal bei Erwägung der doch noch rein hypothetischen Natur jener der Stütze einer sichern klinischen Beobachtung noch völlig entbehrenden Annahme. Dagegen steht nun freilich die 
grosse Zahl der Basedowsehen Erkrankungen obne eigentlichen ophthalmoskopischen Befund der Entscheidung für die zweite Möglichkeit hindernd im Wege - doch dürfte durch viele negative eine positive Beobachtung nicht ausgeschlossen werden und es wäre jedenfalls in unserem Fall Nachdruck zu legen auf das lange Jahre in boträchtlicher Intensität andauernde Bestehen der Krankheit.

Wollen wir aber durch die Analyse des vorstehenden Falls weiter geführt werden, so kann dies doch nur unter der Voraussetzung geschehen, dass wir das Wesen des Morbus Basedowi in einer vasomotorischen Störung finden und zwar speciell auch den Exophthalmus ausschliesslich auf eine solche zurückführen. Hierüber, sowie über die Rolle, die wir dabei dem Sympathicus zuertheilen, haben wir uns vor der Weiterführung unserer anf die spinalen Augenerkrankungen gerichteten Untersuchung noch auszusprechen. Wir haben umsomehr Anlass hierauf einzugehen, als bei verschiedenen unserer Thierexperimente sich ganz ungesucht Exophthalmus entwickelte. Am 4. Mai 1881 beobachteten wir zuerst dieses Phänomen an einem Kaninchen unter folgenden Versuchsbedingungen:

Der rechte Sympathicus wax $4 \mathrm{~mm}$ unterhalb des Ganglion cervicale supr. durchschnitten worden ohne jeden momentan ersichtlichen Einfluss auf das Auge. Reizung des centralen Stumpfes bewirkt sofortige maximale Pupillendilatation rechts. Dabei ophthalmoskopisch deutliche Verengerung der Gefässe.*)

*). Wir müssen diese und ähnliche Thatsachen bei der Schilderung der Versuche hier schon anticipiren, wenn auch erst später eingehend von ihnen gehandelt werden kann. Ein für allemal sei bemerkt, dass wenn von "Gefässen" schlechtweg die Rede ist, immer die ophthalmoskopisch sichtbaren des Augenhintergrundes, speciell aber die Verzweigungen der Arteria und Vena centralis retinae und nicht die Chorioidealgefässe gemeint sind. Ausserdem ist festzuhalten, dass wenn nicht ansdricklich das Gegentheil bemerkt wird, bei Experimenten am Sympathicus die geschilderten Effecte sich stets auf das gleichseitige Auge beziehen. Selbstverständlich wurden bei allen faradischen Reizungen Stromschleifen, 
Bei dem Versuch einer partiellen Exstirpation des Ganglions tritt, während das Ganglion mit der Pincette gefasst wird, mit einer geringen Erweiterung der Pupille eine deutliche Protrusion des Bulbus auf. Die Gefässe konnten in diesem Augenblick nicht beobachtet werden. Nun wird der erhaltene Rest des Ganglions mit starkem Inductionsstrom gereizt: maximale Pupillenerweiterung - Exophthalmus Gefässverengerung. Diese drei Erscheinungen verschwinden und kommen wieder jedesmal bei wioderholtem Oeffnen und nach einigen Minuten Wiederschliessen des Stroms. Während also, wie oben angegeben, die Reizung des Sympathicus $4 \mathrm{~mm}$ unterbalb des Ganglions wohl Pupillenerweiterung und Gefässverengung, nicht aber Exophthalmus zur Folge gehabt hatte, gesellte sich bei Reizung des Ganglions dieses Phänomen den übrigen hinzu. Als wir es hier das erste Mal. beobachteten, dachten wir in erster Linie, es möchte durch die Wirkung der glatten Muskelfasern verursacht sein. Wir durchschnitten deshalb sofort das obere Lid derart, dass diese Wirkung sicher ausgeschlossen war: der Exophthalmus kehrte wiederholte Male in gleichem Maasse wieder. Allein als wir nun das Thier tödteten und beide Bulbi enucleirten, floss auf der Seite der Operation reichliches venös gefärbtes Blut aus der Orbitalhöhle, während die andere Orbita blutleer war.

Wir standen so vor dem merkwürdigen Resultat, dass die gleiche Reizung Gefässeontraction im Augenhintergrund und Hyperämie im Hintergrund der Orbita bewirkt hatte. Da die Beobachtung verschiedener gleichzeitiger Phänomene ohnedies schon sehr schwer war, so wurde in diesem wie in allen unsern folgenden Experimenten der Stand der Blutfülle der Ohren stets ausser Acht gelassen. Zwei Tage darauf gelang es uns wieder unter den gleichen Versuchsbedingungen Exophthalmus zu erzeugen, nur hatten wir diesmal aus andern Gründen die Carotis communis nach

unipolare Ströme etc. berücksichtigt resp. ansgeschlossen, und die Bemerkungen Rosenthal's im neuesten Band von Dubois-Reymond's Archiv, die gerade für derartige Experimente am Hals hochwichtig sind, sehr beherzigt. 
doppelter Unterbindung durehschnitten, was an dem Versuche gar nichts änderte, wie wir überhaupt, um dies gleich hier zu bemerken, für das Kaninchen die früheren Angaben von Leber und Schöler vollständig bestätigen können, dass Unterbindung einer Carotis keinen Einfluss auf die Circulation des betreffenden Angenhintergrundes äussert.

Am 11. Mai fand sich bei einem erneuten Versuch am Kaninchen, als der Sympathicus frei präparirt wurde, ein Verbindungsast zwisehen ihm und dem Vagus, von diesem spitzwinklig nach unten abgehend, $2 \mathrm{~cm}$ unterhalb das Gangl. supr. Derselbe verläuft schief über die Carotis und endigt nach einem $4 \mathrm{~mm}$ langen Verlauf in den Sympathicus. Als dieser Verbindungsast zu Beginn des Versuchs mit der Pincette aufgehoben wird, tritt starker Exophthalmus ohne Pupillenerweiterung auf, der gleichseitige rechte Bulbus widerstrebt dem Versuche, ihn zu reponiren, während der linke normale sich leicht zurückdrängen lässt; der Exophthalmus bleibt kurze Zeit ungeändert bestehen, vermindert sich dann aber ganz allmählich, während andere nicht hierhergehörige auf die Pupille bezügliche Versuche fortgesetzt wurden. Durch keine weitere Reizung, weder des geschilderten Nervenzweigchens, noeh des Sympathicusstamms, noch des Ganglion war dann aber mehr Exophthalmus weiter zu erzielen. Es muss hier noch bemerkt werden, dass faradische Reizung jenes Zweigchens Pupillenerweiterung zur Folge hatte und dass dieser Effect andauerte, als es vom Vagus getrennt war; es war dabei sorgfältig durch Glimmerblättchen isolirt worden und der Fffect seiner Reizung cessirte vollständig, als der Sympaticus oberhalb seiner Eintrittsstelle in denselben durchschnitten wurde.

Am 16. Mai spannten wir ein Kaninchen in Banchlage auf das Versuchsbrett, eine Schnur um den Nacken zieht den Kopf nach vorn; zur Erleichterung der ophthalmoskopischen Untersuchung wird eine Papprolle unter den Hals gelegt. Als der Kopf mit der Schnur fest angezogen und der Hals auf die Rolle gedrückt wird, treten beide Bulbi stark aus ibren Höhlen, so dass sie sogar spontan luxiren. Beim Versuch, die Bedingungen dieser Erscheinungen zu ergründen, wird zuerst 
gefunden, dass gleichreitig mit dem Exophthalmus eine Verlangsamung der 36 per $1 / 4$ Min. in der Norm betragenden Pulsfrequenz auftritt. (Vagusreizung?). Die Gefässe im Augenhintergrund sind unverändert; nun wird die Rolle unter dem Hals weggelassen und der Strick, der nur auf Nacken und Seitentheile des Halses drückt, stark angezogen; es tritt wieder bedeutende Pulsverlangsamung, aber viel schwächere Protrusion des Bulbus anf. Nun wird der Strick an die Schneidezähne angelegt und der Kopf so angezogen, was ganz ohne Resultat bleibt. Hierauf wird beiderseits auf die Gegend der Vagi starke Digitalcompression ausgeübt. Es folgt deutliche Pulsverlangsamung, aber kein Exophthalmus. Zur Controle werden nun noch einmal die anfänglichen Bedingungen hergestellt mit genau dem gleichen Resultat. Jetzt wird der Kehlkopf allein comprimirt, es ergiebt sich in der Dyspnoe Unregelmässigkeit des Herzschlags, aber nicht die charakteristische Pulsverlangsamung von vorhin. Die Vena jugularis für sich allein sicher zu comprimiren, schien uns nicht möglich, wir wollten daher das auffallende Phänomen vorläufig verlassen, es drängte sich uns aber sofort wieder unbeabsichtigt auf, als wir nun zur ophthalmoskopischen Untersuchung den Kopf des Thieres wieder fester zu fixiren gezwungen waren. Es trat aber jetzt nur linksseitiger Exophthalmus ein mit beträchtlicher gleichseitiger Pupillenverengerung. Wir finden, dass der Strick links unter dem Unterkiefer liegt and so auf die Weichtheile des Halses drüeken kann, während er sich rechts auf das Unterkieferbein gelegt hat, ohne den mindesten Druck auf den Hals auszuüben. Nun wird der Kopf so gelegt, dass auch die rechte Seite des Halses gedrückt wird. Sofort tritt doppelseitiger Exophthalmus anf, dabei zeigt sich auf beiden Augen ophthalmoskopisch nicht die mindeste Gefässveränderung, wohl aber an der Pupille das sehr bemerkenswerthe Verhalten, dass jedesmal die Protrusion des Bulbus von einer starken Verengerung begleitet ist, und zwar in besonders charakteristischer Weise einseitig bei dem geschilderten einseitigen Exophthalmus. Beleuchtungseinflüsse waren ausgeschlossen. Wir tödteten auch dieses Thier durch Stich in die Medulla oblongata, ohne irgend welchen weiteren experimentellen Eingriff an ihm vorzunehmen; nach Herausnahme der Bulbi zeigen sich im Hintergrund der Orbita sehr stark gefüllte Venen, nach völliger Ent* leerung der Augenhöhlen fliesst noch anhaltend aus beiden 
eine Menge dunkelrothen Bluts; dagegen wax weder in den Hirnsinus, noch in den. Jugularvenen eine abnorme Blutfülle zu. constatíren.

Nun ist gleich zu bemerken, dass wir noch an vielen Kaninchen unter anscheinend ganz denselben Bedingungen experimentirt haben, obne je einen Exophthalmus zu Gesicht za bekommen.

So sehr es uns auch lockte, die näheren Bedingungen speciell dieser Erscheinung zu ergründen, so mussten wir uns doch sagen, dass wir uns hierdurch zu weit von unserem eigentlichen Ziele entfernen würden; was wir aber schon aus den vorliegenden Thatsachen za schliessen berechtigt sind, ist die Existenz eines nervösen Mechanismus, der einen deutlichen Einfluss auf die retrobulbäre Blutfülle ausübt. Denn, dass alles nicht etwa bloss auf mechanisch bedingte Stauungserscheinungen zurückzuführen sei, hat sich doeh gewiss aus vorstehenden Versuchen zur Evidenz ergeben. In den letzt aufgeführten Beobachtungen, die, weil bei unversehrter Haut gemacht, etwas zweifelhaft erscheinen könnten, ist dafür auf die gleichzeitige beträchtliche Pulsverlangsamung um so mehr Gewicht zu legen. Wenn wir aber die thatsächliche Existenz eines solchen Mechanismus nachdräeklich hervorheben, so verzichten wir doch vollständig auf jeden Versuch, uns irgendwie auf eine Erklärung seiner Bahnen einzulassen. Dass die Verhältnisse hier ganz enorm complicirte sind, geht schon aus der einfachen Erwägung der Widersprüche hervor, die in den Ergebnissen unserer Versuche enthalten sind. Zuerst hatten wir retrobulbäre Hyperaemie gleichzeitig mit Gefässverengerung im Augenhintergrund und Pupillenerweiterung (bei Reizung des Ganglions). Dann fanden wir bei Reizung jenes Nervenzweigchens einen Exophthalmus ohne nachweisbare Veränderungen im Augenhintergrund, aber wieder so, dass von der gleichen Stelle aus Pupillenerweiterung auftrat, während eine ganz unerklärliche Pupillen- 
verengerung im letzten Fall bei wieder indifferenten Gefässen des Hintergrunds sich mit dem Exophthalmus combinirte, und endlich scheitert vollends jeder Brklärungsversuch an der Combination mit dem Symptom der Vagusreizung, der Pulsverlangsamung; denn wollten wir etwa im Sinne der allerdings einheitlich durchdachten Filehneschen Hypothese des Basedow'schen Exophthalmus uns die Sache zurechtlegen durch die Annahme eines Drucks auf Nervenfasern, die normaliter einen tonischen Einfluss auf das retrobulbäre Gefässsystem ausüben, so müssten wir dann doch wenigstens, um die Analogie mit den Symptomen des Morb. Basedowi complet zu machen, statt der Symptome der Vagusreizung die der Lähmung erwarten, und nehmen wir vollends im letztern Falle noch die ganz räthselhafte Pupillenverengerung hinzu, die nach landläufigen Begriffen wieder als die Symptome von Sympaticuslähmung gedeutet werden müsste, so verlieren wir uns in ein völliges Labyrinth.

Sehr wichtig aber für uns ist die offenbare Unabhängigkeit des retrobulbären Gefässnervensystems von dem des Augenhintergrunds. Sie mögen allerdings, vielleicht vom Ganglion supremum an, in den gleichen Bahnen verlaufen - man könnte vielleicht jenes Nervenzweigchen, das wir gesehildert, als eine aussergewöhnlicherweise tiefer aus der Vagus in die Sympatiousbahn übertretende Verbindung ansehen - jedenfalls aber werden ihre Abgangsstellen aus dem Centralnervensystem weit auseinander liegen. Wir haben allen Grund, anzunehmen, dass individuelle $\mathbf{A b -}$ weichungen hier eine grosse Rolle spielen, wie auch schon von Filehne in seinen Untersuchungen uber Amylnitritwirkungen nachdrücklich darauf hingewiesen wurde, dass bei versehiedenen Individuen derselben Thierspecies dieselbe vasomotorische Leitungsbahn, einmal im Halssympathicus vertreten sein, das andere Mal auf ganz anderem Wege zum Kopf oder wenigstens zum Ganglion 
supremum treten kann. So hat Filehne in seinen auf experimentelle Erzeugung von Exophthalmus gerichteten Experimenten auch gefunden (vergl. S. 142), dass der Effect von den Corp. restiformia aus auch eintrat, wenn beide Sympathici am Hals durchschnitten worden waren. Wenn nun wir dagegen eben vom Halssympathicus aus Exophthalmus erzeugen konnten, so scheint dies eine weitere Bestätigung des obigen principiell richtigen Grundsatzes zu sein.

Ehe wir uns nun wieder dem uns zunächst interessirenden Gefässnervensystem des Augenhintergrunds zuwenden, sehen wir uns durch einige weitere Nebenresultate unserer Versuche genöthigt, noch eine dritte Reihe von Thatsachen zu berücksichtigen, die einen weiteren relativ selbstständigen nervösen Einfluss auf das Ange, und zwar hier auf den Uvealtractus wahrscheinlich machen. Wir kntupfen hier wieder an den schon oben beschriebenen klinischen Fall an, in dem die deutlichen Symptome rasomotorischer Störung im Gesicht in Combination erschienen mit glancomatösen Erscheinungen am Auge. Als einen besonders prägnanten gleichgearteten fügen wir ihm nachfolgenden an:

Ein vor Jahren von doppelseitigem Glaucom befallenes weibliches Individuum erweist sich bei der Untersuchung ihres Allgemeinzustandes nicht nur überhaupt im höchsten Grade neuropathiseh, sondern zeigt speciell eine derartige Irritabilităt des Gefässnervensystems der Haut, dass ein leises Streichen über eine Hautstelle, besonders am Rücken, genügt, um stundenlang bestehen bleibende breite rothe Striemen zu erzeugen. Dabei hat sie auch gerötheten Kopf und die charakteristischen Klagen über Brennen und Hitze in der Kopfhaut, weshalb sie auch von einer sehweren Entzündung der Knopfknochen befallen zu sein glaubt.

Es braucht nun nur erinnert zu werden an die höchst instructiven Fälle, die Wegner im Arch f. Ophthalm. XII. 2 veröffentlicht hat, sowie an die im Anschluss daran von 
ihm gemachten Versuche über nervöse in dieser Richtung wirkende Einflüsse. Wenn er dem Nervus trigeminus dabei eine dominirende Rolle zuertheilt, so haben wir uns selbstrerstandlich hier nicht auf das Detail der viel discutirten Pathogenese des Glaucoms einzulassen und wollen nur bemerken, dass in dem Gros der Fälle es doch in letzter Instanz sicher als nervöse und zwar vasomotorische Störung aufzufassen ist, wobei freilich zu beachten ist, dass auch gewiss in einer Reihe von Fällen die Reflexauslösung vom Auge selbst ausgeht, wobei dann eine idiopathisehe nervöse Störung nicht angenommen zu werden braucht. Dass es aber in gewissen Fällen auch auf einer solchen, oder wenigstens auf einer, deren Reflexauslösungsstelle extraocular zu suchen ist, beruht, machen doch Fälle wie die vorstehenden höchst wahrscheinlich. Für uns hat aber die Rücksichtnahme auf das ganze Kapitel dieser pathologischen Erscheinung nur insofern Bedeutung, als wir ihre Localisation jedenfalls im Uvealtractus suchen dürfen und wir somit einen Anknüpfungspunkt für die Erklärung einiger auffallender Erscheinungen gewinnen, die wir auf Sympathicusreizung an der Iris des Kaninchens auftreten sahen. Es handelte sich hier jedoch nicht direct um Steigerung des intraocularen Drucks, deren feinere Messung wir wenigstens nicht berücksichtigen konnten, sondern um folgendes zuerst am 12. Mai 1881 beobachtete Verhalten:

Ein Kaninchen, dem am Tag zuvor der rechte Sympathicus durchschnitten worden war und dessen Wunde stark eiterte, zeigte auf der entgegengesetzten linken Iris ein im äussern untern Theil den Pupillarrand schräg von aussen oben nach unten innen überziehendes und mit der Hinterwand der Cornea verlotthetes flockig fibrinöses Exsudat von $8 \mathrm{~mm}$ Länge. Im Chorioidealgefüsssystem, sowie in der Spannung ist keine Differenz zwischen beiden Augen zu bemerken. Bei der einige Stunden darauf gemachten Section des in Folge 
von Amylnitritwirkung gestorbenen Thieres war das Exsudat beinahe völlig geschwunden.

Ein gleiches Exsudat konnten wir noch einmal bei einem Kaninchen constatiren, aber diesmal auf der entsprechenden Seite. Bezuglich des gekreuzten Verhaltens ist noch hinzuzufügen, dass im vorstehenden Fall die Wirkung auf die Pupille auch eine gleichseitige war, indem ihre Weite Rs. 6, Ls. $7 \mathrm{~mm}$ betrug and ebenso liess sich auch hier eine dem durchschnittenen Sympathicus entsprechende gesteigerte Gefässfüllung und Temperatur des gleichseitigen Ohrs constatiren. Wir erinnern auch noch an den oben geschilderten klinischen Fall von Kreuzung der Störungen im Gesicht und Auge.

So wenig als der Exophthalmus oben, erlaubte uns das Endziel unserer Arbeit diese Erscheinung ins Detail ihrer Bedingungen zu verfolgen, was auch um so schwieriger gewesen wäre, als auch hier unter 12 Thieren, die wir in gleicher Weise zu andern Zwecken operirten, mit Ausnahme der zwei, keines mehr irgend etwas Aehnliches bot. Auch hier war uns nur werthvoll, die Andeutung einer neuen Reihe von Erscheinungen gefunden zu haben, die sich in ungezwungenster Weise auf Störungen der Gefässinnervation zurüekführen lassen; wir brauchen ja die Cohnheim'sche Entzündungstheorie hierbei nur zu erwähnen.*)

Kehren wir noch einmal für einen Augenblick zu dem retrobulbären Gefässnervensystem zurück, von dem wir

*) Vergl. zu Vorstehendem: Grünhagen u. Jesner, Ueber Fibrinproduction nach Nervenreizung. Centralbl. f. prakt. Augenheilkunde 1880, S. 181 . Hier finden sich ganz analoge Versuchsergebnisse, nur dass der gereizte Nerv bier der Ram. ophthalm. nerv. trigemini war. Wenn auch mit unserer Aufgabe nicht direct zusammenhängend und wohl noch sehr direeter Beweise bedürftig, können wir doch die Bemerkung nicht unterdrüeken, dass sowohl die Durchsicht der in der Literatur enthaltenen zahlreichen und zum Theil so widerspruchsvollen Experimente als auch die Ver- 
oben ausgingen, so wäre es gewiss auch ganz falseh, anzunehmen, dasselbe sei nun immer besonders eng gerade an den N. sympathicus geknüpft. Wir haben schon oben die Wichtigkeit individueller Verschiedenheiten betont, wir möchten diese Betrachtungsweise dahin ausdehnen, dass überhaupt die allerverschlungensten Bahnen verschiedenster physiologischer Dignität and räumlich weit getrennten Ursprungscentren entstammend, in Halssympathicus und Vagus anatomisch beisammen liegen. Es sei hier nochmals an die wichtigen Experimente Filehne's erinnert*), der die Bahn, von der aus sich Exophthalmus erzeugen liess, in den Corp. restiformia traf. Dort oder viel wahrscheinlicher noch weiter centralwärts hätten wir uns eine eventuelle Localisation des Basedow'schen Exophthalmus zu denken, der freilich in den meisten Fällen wohl nur als auf functioneller Störung beruhend $\mathrm{zu}$ betrachten ist.

gleichung derselben mit dem von uns selbst Beobachteten doch den Gedanken am Meisten nahe legt, dass die in der Bahn des Trigeminus verlaufenden auf die Circulation im Ange Einfluss übenden Fasern zum grossen Theil dieselben sind, die man am Hals in Sympathicus trifft. Ein von uns gelegentlich gemachter Versuch, hierüber directen Aufschluss za erhalten, ergab allerdings kein Resultat. Wir fanden nz̈mlich den gleichseitigen Trigeminus eines 10 Tage nach Exstirpation eines Gangl. sup. gestorbenen Kaninchens, in dem wir möglicherweise degenerirte Fasern zu finden hoften, frei von solchen. Doch dürfte dies schon deswegen gar nichts.beweisen, als weder die Möglichkeit einer Kreuzung der Fasern, wo alsdann der entgegengesetzte Trigeminus untersucht werden müsste, noch die der Interposition eines näheren trophischen Centrums in der Art, dass die Fasern z. B. das Ganglion Gasseri passirten, wo alsdann gar keine secundäre Degeneration zu erwarten wäre, ausgeschlossen werden kann. Für gekreuztes Verhalten sprach auch das eine unserer obigen Versuchsresultate und es sei in dieser Richtung noch auf die angeführte Mittheilung Grünhagen und Jesner's verwiesen, die nicht gekreuzte, sondern doppelseitige Wirkung beobachteten, jedoch schwächer auf der entgegengesetzten Seite.

*) Zur Pathogenese der Basedow'schen Krankheit. Sitzungsberichte der Erlanger physikalisch-medicin. Societät. 14. Juli 1879. 
Wir haben dann oben verschiedene Male zufällig die Bahn an anderer Stelle getroffen. Mag sie dann immerhin zum Theil im Sympathicus verlaufen, so darf man sich doch nie mehr etwa darüber wundern, dass dann nicht gleichzeitig auch andere, sonst mit Sympathicusläsionen verknüpfte Störungen auftreten, also z. B. keine Pupillenveränderung; denn bekanntlich hat Albr. v. Graefe unter nahezu 200 Fallen von Morb. Basedowi nie eine solche beobachtet. Dass diese Combination dann aber doch wieder vorkommt, dafür spricht sich Eulenburg aus*), der auch Pupillenveränderung in Fällen von ächtem Morb. Basedowi niemals gesehen hat, dagegen Fälle von comprimirender Struma mit geringem einseitigem Exophthalmus und Pupillenerweiterung zugiebt.**) Diese entsprächen genau unseren obigen den Sympathicus treffenden Experimenten. Hier, wo die Leitungsbahn getroffen ist, können dann natürlich auch beide Fasergattungen betheiligt sein. Man vergleiche noch die Falle von Nitzelnadel, Samelsohn u. A., die bei Sattler (Morb. Basedowi in GraefeSämisch's Handbuch S. 960 ff.) citirt sind. Von wie verschiedenen Punkten aus und in wie verschiedener Combination nun aber auch Exophthalmus zu Stande' kommen mag, darüber, dass die nächste Ursache in einer retrobulbären Hyperämie besteht, ist man wohl so ziemiich einig. Diese Auffassung erhält ja auch durch unsere Versuchsergebnisse eine kräftige Stütze und wir erklären uns den dabei sich abspielenden Vorgang am Besten durch den Vergleich mit einem Schwellgewebe, das gewiss auch

*) Ziemssen's Handbuch: Vasomotorisch-trophisehe Neurosen. S. 82.

**) Auf die sich hier wieder erhebende so ausserordentlich verwickelte Frage, wie diese Papillenerweiterung also Reizsymptom dęs Sympathicus mit der vorauszusetzenden retrobulbären Hyperämie, also nach bisherigen Begriffen Lähmungssymptom, zu vereinigen ist, können wir uns aus den schon früher angegebenen Gründen nicht einlassen. 
schon physiologisch im Hintergrund der Orbita nicht ohne Bedeutung wäre. Wir brauchen in dieser Richtung nar hinzuweisen auf die Anforderungen, die durch die Augenbewegungen an die Verschieblichkeit der hinter ihnen gelegenen Theile gestellt werden, und denen gewiss durch ein beständig nervös regulirtes erectiles Gewebe am Besten genügt wird.

Indem wir aber nun definitiv mit allem hierauf Bezüglichen abbrechen, kehren wir zur Gefässinnervation des Augenhintergrundes zurück mit dem ausdrücklichen Bemerken, dass wir ein eventuelles System, das bei den neuroparalytischen Hornhantaffectionen in Betracht käme, absichtlich deswegen gänzlich bei Seite lassen, weil nichts in unsern Experimenten uns hierauf geführt hat. Dooh sei es hier ausdrücklich erwähnt, weil es eine grosse Rolle zu spielen haben wird, wenn einmal die Zeit zu einer vollständigen Darstellung der auf das Auge wirkenden nervösen Einflüsse gekommen ist.

Wir verliessen oben unser eigentliches Thema, verführt durch den für unsere Theorie verlockenden Befund atrophiseher Vorgänge am Opticus bei Basedow'schem Exophthalmus, zugleich aber auch geleitet von der Hoffnung, durch einen raschen Ueberblick über die verwandten Gebiete eine festere Basis zn gewinnen für die Würdigung des Einwandes, den wir uns machten, dass nämlich die mit einer gewissen Sicherheit als vasomotorische zu betrachtenden Störungen am Auge sich nicht in Opticuserkrankungen äussern. Indem wir nun nochmals hervorheben, dass wir keinen zu grossen Nachdruck auf jene vereinzelte Beobachtung in dieser Richtung legen und besonders auch noch auf die Erklärungsmöglichkeit aufmerksam machen möchten, wonach es sich um eine retrobulbäre Neuritis handeln könnte, direct mechanisch bedingt eben durch die pathologischen schon so lange bestehenden Veränderungen im Hintergrund der Orbita, so haben wir. 
dagegen in letztgenannter Hinsicht allerdings den prineipiell hochwichtigen Gesichtspunkt gewonnen, dass Leitungsstörungen im Verlauf des Sympathicus durchaus nicht alle Fasern desselben gleichmässig zu betreffen und besonders auch durchaus nicht die gleichen Effecte zu setzen brauchen wie Läsionen an centralen Ursprungsstellen, die ausserdem selbst viel mehr irritativen, entzündlichen Charakter tragen können. Wir werden zwar gut thun, von unseren Erklärungsversuchen die Annahme eigentlicher trophischer Centren fern zu halten, um nicht ignotum per ignotius zu erklären, wir werden aber andererseits auch uns die Möglichkeit der Annahme nicht verschliessen, dass von Stellen im Rückenmark aus vasomotorische Fernwirkungen auf den Augenhintergrund stattfinden, deren Mechanismus uns nicht einmal unter physiologischen Verhältnissen völlig bekannt ist und noch weniger seine eventuell unter pathologischen resultirenden Modificationen. Dass aber ein solcher Einfluss überhaupt existirt, lässt sich, streng genommen, schon aus der klinischen Thatsache der Gefässerweiterung bei den mechanischen Sympathicusläsionen beweisen. Es wäre ja schon durch diesen Befund höehst wahrscheinlich gemacht, dass auch für die Gefässe des Augenhintergrunds ein durch die Bahn des Sympathicus vermittelter tonischer Einfluss des Centralnervensystems bestände, der dann bei Sympathicusläsionen in Wegfall käme.

Diese Annahme experimentell auf ihre Richtigkeit zu prüfen, war nun unsere nächste Aufgabe. Wir wählten zwei Methoden, um uns über die Sehwankungen des Kalibers der Gefässe zu informiren:

1. Faradische Reizung des Halssympathicus beim Kaninehen;

2. Einwirkung von Amylnitrit auf den Menschen, das Kaninchen, und den Frosch unter Beobachtung des Kreislaufs in seiner Membrana hyaloidea.

จ. Graefe's Archiv fiur Ophthalmologie, XXVIT. 3. 
Wir bemerken zur Methode im Voraus, dass immer sowohl im aufrechten, als im umgekehrten Bild ophthalmoskopirt wurde, und dass wir sehr bedauerten, wegen der zu grossen technischen Schwierigkeiten nicht auch die Circulation der Frosehhyaloidea bei Sympathicusreizung studiren zu können. Ebenso wäre es uns sehon hier, wie bei später zu beschreibenden Versuchen noch mehr, höchst werthroll gewesen, wenigstens bei Amylnitriteinwirkung gleichzeitige ophthalmoskopische Beobachtungen an der Hyaloidea und mikroskopisehe an der Schwimmhaut des Frosches machen zu können, allein auch dies überstieg unsere Kräfte. Die anfangs auch gemachten Versuche, den Menschen bei Electrisirung am Hals zu ophthalmoskopiren, gaben wir bald als zu unklar und wenn sie je wirksam sein sollten, viel zu schmerzhaft auf.

Deber die Möglichkeit, die Weite der Gefässe des Augenhintergrunds dureh Sympathicusreizung oder Durchschneidung $\mathrm{zu}$ beeinflussen, lagen bis jetzt widersprechende Angaben vor.

Klein und Svetlin, die auch die frühere Literatur über den Gegenstand angeben (in: Psychiatrische Stndien aus der Klinik von Leidesdorf. Wien 1877 S. 89 ff.), erklären auf Grund ihrer Versuche an Kaninchen und Katzen, sowie von Galvanisation am Mensehen, „dass die Innervation der Gefässe des Augengrundes durch andere Bahnen geschehen müsse, als durch die aus dem Halstheil des Sympathicus entstammenden Geflechte." Vor ihnen hatten aber verschiedene Experimentatoren das Gegentheil behauptet, wie aus den Literaturangaben bei ihnen zu ersehen ist. Und ferner steht ihnen gegenüber die gewichtige Angabe Leber's (1. c. S. 353: „Die Netzhautarterien stehen unter der Wirkung des Halssympathicus. Ich habe am Kaninchen bei Reizung dieses Nerven deutliche Verengerung derselben beobachtet.") Die andern im Wesentlichen 
gleichlautenden Angaben von,Schöler und Becker mögen am angeführten Orte bei Leber nachgesehen werden. Schöler berücksichtigte auch die Gefässerweiterung nach Sympathicusdurchschneidung.

Aus unsern Versuchen haben wir ausser den schon oben bei der Erzengung des Exophthalmus gelegentlich erwähnten Effecten noch folgende Resultate einzeln aufzuführen:

Reizung des freigelegten Halssympathicus mit starkem Inductionsstrom, auf einer Strecke $5 \mathrm{~mm}$ unter dem Ganglion supr. bis zu diesem selbst, bewirkte bei zwei Kaninchen bedeutende Gefässverengerung, die nach Unterbrechung des Stroms in $1 / 2$ Min. wieder verschwand. Nach hänfig wiederholten Versuchen trat der Effect schliesslich nicht mehr ein. Er coincidirte immer mit starker Pupillenerweiterung, - wie wir oben sahen, einmal mit Exophthalmus. In der Promptheit and Intensität der Wirkung war kein Unterschied zu bemerken, ob der Reiz etwas näher oder ferner vom Ganglion oder auf dieses selbst applicirt wurde.

Nach Durchschneidung des Halssympathicus sowie nach Exstirpation des Ganglions trat in vier Fällen kein nnmittelbarer Effect auf - die am Leben erhaltenen Thiere zeigten aber sämmtlich am folgenden Tag auf der operirten Seite weitere Gefässe, eine Differenz, die noch mehrere Tage bis zum Tode der Thiere anhielt.

Die Gefässerweiterung war nicht etwa schwer, sondern stets sehr deutlich und leicht zu constatiren. Die Möglichkeit, dass Klein und Svetlin, die ausser an Katzen auch an Kaninchen experimentirten und zu völlig negativem Resultat gelangten, doch richtig beobachtet haben, lässt sich nicht gänzlich in Abrede stellen, da die Annahme, dass unter ihren Kaninchenindividuen sich zufällig keines mit im Sympathicus verlaufenden Gefässnerven- 
fasern befunden hätte, wenn anch nicht sehr wahrscheinlich, doch immerhin nicht undenkbar ist. Es ist in dieser Richtung an das oben Gesagte (S. 138) zu. erinnern.

Ueber die Wirkungen des Amylnitrits auf die Gefässe des Angenhintergrunds lagen bis jetzt ebenfalls widersprechende Angaben vor. Pick (Ueber das Amylnitrit. Berlin 1877. S. 34) sagt: „Eine Erweiterung der Retinalgefässe findet nicht statt." Gestützt wird dieser Satz durch einige auch von Sämisch controlirte Versuche am Menschen. Ebenso meint Sam el so hn in einer ganz neuerdings erschienenen Mittheilung (Centralblatt für Augenheilkunde 1881 S. 200), auf die wir wie auf die folgende noch zurückzukommen haben werden, Amylnitrit habe keinen sichtbaren Einfluss auf die Gefässfüllung der normalen Papille, während er für den pathologischen Fall, den er der dabei gefundenen abnorm engen Gefässe wegen mit Amylnitrit behandelte, die prompte Wirkung auf Erweiterung gerade hervorhebt. Dagegen hatte vorher Deutsehmann, der ähuliche Fälle in V. Graefe's Archiv (Bd. 27 S. 311) beschrieben hatte, ausdrücklich angegeben: „Es gelingt unschwer beim Menschen und besonders bequem beim Kaninchen, naoh Inhalation einiger Züge von Amylnitrit auf der Papille eine Menge feinerer Blutgefässchen erscheinen zu sehen, die vordem kaum oder gar nicht wahrnehmbar waren."

Wenn wir hinzufügen, dass auch die vorher sichtbaren grösseren eine deutliche Erweiterung zeigen und dass in vielen Fällen nach Amylnitrit am Mensehen und Kaninchen ein vorher nicht sichtbarer Venenpuls zum Vorschein kommt, so haben wir das Resultat unserer Untersuchungen angegeben. Sie wurden am Menschen in grosser Ausdehnung angestellt und gleichzeitig dabei auf Bulbusspannung, Pupillenweite und conjunctivale Gefässfüllung geachtet. 
Das auf die Pupille Bezugliche werden wir unten an seinem Ort anführen.

Aus 29 Versuchen an verschiedenen Individuen aller Lebensalter können wir das Eacit ziehen, dass in der Spannung nie ein palpabler Unterschied wahrzunehmen war, dass die Röthung der Conjunctiva stets ungefähr gleichzeitig mit der Hyperämie des Augenhintergrunds auftrat, aber immer erst eine messbare Zeit nach der Röthung. der Wangen. Die Zeit, die rom Beginn der Inhalation bis zum Sichtbarwerden von ophthalmoskopischen Veränderungen verfloss, schwankte zwischen 30 Secunden bis 4 Minuten. Häufig zeigte sich nicht nur capillare Hyperämie und Erweiterung der gröbéren arteriellen Gefässe, sondern auch stärkere Füllung und dunklere Färbung der Venen. In drei Fällen exquisiter Venenpuls.*) Dessen Erklärung schien uns von Anfang an sehr einfach. Bei dem beträchtlich herabgesetzten arteriellen Blutdruck wird die vis a tergo für die Venen geringer und dadurch kann zumal in den verbreiterten Venen die immer vorhandene Pulsation etwas ergiebigere Excursionen machen und so sichtbar werden. Ein solcher directer Einfluss der Arterien auf die Venen ist ja im Verzweigungsgebiet der Art. centralis retinae völlig erklärlich, sobald man in Betracht zieht, dass hier Endarterien sich finden, somit der Ausgleich in einem verzweigteren Capillarnetz fehlt. Ganz entsprechend hat Mosso auch im Hirn, wo die gleichen mechanischen Bedingungen durch die Anordnung der End̈arterien bestehen, normaliter Venenpuls nachgewiesen. Alle Verănderungen waren nach Aussetzen der Inhalation immer im Verlanf von höchstens 2 Minuten völlig wieder geschwunden.

In Bezug auf das Lebensalter schien sich die Differenz

*) Wadsworth und Patnam haben ihn auch schon auf Amylnitrit gesehen. 
zu ergeben, dass ältere Individuen langsamer und schwerer reagirten, während es bei Kindern stets ganz besonders rasch und leicht ging. Es dürfte dieser Punkt wohl noch genau nachgeprüft werden.

Ein bemerkenswerthes Verhalten liess sich an der oben geschilderten Patientin (S. 131) mit einseitiger Sympathicuslähmung beobachten: Während die Gefässe des gesunden Auges sich wie gewöhnlich auf Amylnitrit erweiterten, blieben die des afficirten, die vorher schon weiter waren, vollständig unverändert.

Die Versuche am Kaninchen ergaben in Hinsicht auf den Augenhintergrund keine Verschiedenheit rom Menschen - wir konnten alle dort gesehenen Phänomene hier bestätigen, besonders auch das Auftreten von Venenpuls, das Herr Prof. Michel auch mehrmals ausdrücklich zu eontroliren die Güte hatte.

Beim Frosch ergab sich constant eine bedentende Verlangsamung des Kreislaufs in der Hyaloidea zu Anfang der Amylnitritwirkung, die bis zum völligen Stillstand der Circulation bei stärkeren Dosen sich steigerte. Hierbei wurde jedoch der Herzschlag direct nie beobachtet und da Pick schon angiebt, dass beim Frosch im Gegensatz zum Sängethier der Herzschlag entschieden verlangsamt wird, so liesse sich die Erklärung für das vorliegende Phänomen auch durch eine immer langsamere schliesslich ganz verschwindende Herzaction geben. Die von Pick an der Schwimmhaut des mit Amylnitrit behandelten Frosches gemachten Beobachtungen stimmen jedenfalls vollständig mit unseren an der Hyaloidea. Uebrigens wäre doch ein völliger Herzstillstand schwer anzunehmen, da die Thiere sich wieder erholten, and dass ein. Stillstand der Circulation in der Hyaloidea nicht nothwendig mit völligem Herzstillstand sich decken muss, sondern auch in relativer Unabhängigkeit von der Herzaction sich zeigen kann, werden unsere gleich aufzuführenden Versuche von Rücken- 
marksreizung beim Frosch mit gleichzeitiger Beobachtung der Hyaloidea und des blosgelegten Herzens zeigen.

Die Theorie der Amylnitritwirkung unterliegt bekanntlich noch einer Controverse. Hierzu einen Beitrag zu liefern, lag nicht in unserer Aufgabe. Mag das Amylnitrit nach Pick auf die peripheren Nervenverzweigungen in den Gefässen selbst wirken, oder nach Filehne möglichst central angreifen, für uns handelte es sich nur darum, uns desselben als eines Reagens darauf zu bedienen, $a b$ überhaupt. Schwankungen im Kaliber der Retinalgefässe in gleicher Weise wie für das übrige vom Halssympathicus abhängige Kopfgefăssgebiet nachzuweisen sind. Wie uns dies für Amylnitrit gelungen ist, so hätten wir auch gerne noch die Gegenprobe mit einem Mittel gemacht, von dem Gefässverengerung zu erwarten gewesen wäre - es ist hier wohl in erster Linie an Injection von Morphium zu denken. Die naheliegenden Schwierigkeiten der Experimentation am Menschen gestatteten uns nicht, bei diesem die Sache mit gleicher Leichtigkeit zu verfolgen, wie dies glücklicherweise die rerhältnissmässig harmlosere passagere Amylnitritwirkung ermöglichte, und eine grössere Reihe von Thierversuchen waren wir nicht in der Lage, gemeinsam durchzuführen und hielten sie nicht für dringend, zumal da das für uns principiell Wichtige ja schon entschieden war.

Nachdem wir nun die Modificationsfähigkeit des Calibers der Retinalgefässe durch nervöse Einflüsse sowohl überhaupt als speciell auch rom Halssympathicus aus festgestellt hatten, galt es, einen Schritt weiter centralwärts zu gehen und zu versuchen, ob auch von der muthmasslichen Ursprungsstelle jener im Halssympathicus verlaufenden Fasern, dem Rückenmark aus, solche Effecte zu erzielen seien. In dieser Richtung machten wir folgende Versuche: 
Am 26. Mai 1881 wurden durch die intacte Haut eines Kaninchens, bei dem vorher starke faradische Reizung eines blossgelegten Hautnerven am Oberschenkel keinen ophthalmoskopisch sichtbaren Effect erzielt hatte, zu beiden Seiten der Lendenwirbelsäule spitze Electroden eingestochen in der Weise, dass der kürzeste Weg zwischen beiden für den Strom durch's Rückenmark gehen musste. Es wird ein starker Inductionsstrom durchgesehickt. Das Thier geräth sofort in Tetanus sämmtlicher Muskeln. Nach 1 Minute wird der Strom unterbrochen. Die Gefässe sind ein klein wenig enger geworden, die Pupille hat sich ad maximum erweitert und verharrt noch längere Zeit nachher in diesem Zustand. Das Thier ist im ersten Augenblick vollig bewegungsunfähig, die vorher sehr leicht hervorzurufenden Patellarsehnenreflexe sind pöllig verschwunden; nach 2-3 Minuten bewegt sich das Thier wieder vorwärts, aber die Hinterbeine werden noch geschleift.

30. Mai. Kaninchen-Retinalgefässe besonders sehön sichtbar, von gewöhnlicher Weite. Nadelförmige Electroden wurden zu beiden Seiten des Rückenmarks zwischen 4 , und 6 . Brustwirbel durch die unverletzte Haut so weit eingestossen, bis beide, jede anf ihrer Seite, den Wirbelbogen berühren. Es erfolgt 5 Secunden nach Einleiten eines mittelstarken Inductionsstroms Pupillenerweiterung und einige Secunden nachher deutliche Erweiterung der Retinalgefässe - Rollenabstand des Dubois'schen Schlittens $8 \mathrm{~cm}$. Der Versuch wird ein halb Dutzendmal mit gleicher Stromstärke wiederholt. Im Anfang treten ausser den ocularen Symptomen noch klonische Krämpfe in den Hinterextremitäten auf mit Schmerzensschreien. Einige Male zeigt sich weder Wirkung auf die Pupille noch auf die Gefässe. Wenn aber die Pupillen sich erweiterten, so trat auch jedesmal die Erweiterung der Gefässe ein (immer aber erst in einem Moment, wo die Pupille schon ad maximum erweitert war). Wurde der Strom unterbrochen, so verengten sich Pupille und Gefässe jedesmal rasch. Nach 6 maliger Wiederholung des Versuchs unter Verstärkung des Stroms bis zum Rollenabstand von $5 \mathrm{em}$ tritt plötzlich statt der erwarteten Pupillenerweiterung eine Verengerung ein, gleichzeitig wird die Papille auffallend blass, die Gefässe fast ganz blutleer. Das Thier ist todt. Die sofort gemachte Section ergiebt: Thorax und Bauchhöhle unverletzt, sämmtliche Organe derselben sehr anämisch, ebenso das Hirn, 
sowohl Substanz als Häute. Aus dem Wirbelkanal fiesst kein Blut in die Schädelhöble. Nach Eröffnung des Wirbelkanals zeigt sich vom ersten Brustwirbel an nach abwärts bis zum Ende der Wirbelsäule eine ganz enorme Anfüllung des Canals mit dunklem Blut, so dass das Rückenmark comprimirt in der Tiefe liegt und alles in flüssigem Blut schwimmt. Diese Hyperämie endet wie abgeschnitten unter dem 7. Halswirbel, von da ab aufwärts ist der Wirbelcanal so anämisch wie die Schädelhöhle.

Es muss zu diesem Versuch noch hinzugefügt werden, dass während der ersten und zweiten faradischen Reizung sowohl von demjeuigen von uns, der ophthalmoskopirte, als von dem, der die Pupille beobachtete, bemerkt wurde, dass die Bulbi eine Drehung um die verticale Axe nach anssen und oben ausfuhren, so dass ophthalmoskopisch die Papille in ihrem Längsdurehmesser vertical gestellt wird. Es wird dies in einem Augenblick beobachtet, wo keine Reizerseheinungen in der übrigen Musculatur bestanden.

Zur Ergänzung dieser letzteren sonst isolirten Beobachtung, die möglicherweise als beruhend anf Reizung spinaler Partien, die einen Einfluss auf die Augenbewegungen hätten, hingestellt werden könnte, fügen wir noch hinzu, dass wir auch bei einem der späteren Reizungsversuche am blossgelegten Rückenmark noch einmal eine rasche Augenbewegung beim Kaninchen wahrnahmen, für die uns ein sonstiger Anhaltspunkt zur Erklärung fehlte. Wir schenkten diesem Umstand jedoch wenig Beachtung und glauben auch jetzt, kein grosses Gewicht darauf legen zu sollen, führen die Versuche aber der Vollständigkeit wegen hier mit auf, wobei wir später noch bei einem klinischen Fall auf sie, als möglicherweise in Betracht kommend, zurückverweisen werden.

Es folgen nun Versuche mit Einführen der Electroden direct in die Rückenmarkssubstanz:

2. Juni. Einem Kaninchen wird galvanokaustisch der Rückenmarkskanal in der Höhe des ersten Brustwirbels auf 2 cro Ausdehnung eröffnet. Nadelelectroden werden von hinten 
ins Rückenmark eingestochen, ohne Rücksicht darauf, welche Rückenmarkstheile getroffen werden. Auf Durchleitung eines ganz sehwachen Inductionsstroms erweitern sich die Retinalgefässe stark etwa 苦 Minute nach Beginn der Reizung. Nach Unterbrechen des Stroms werden sie wieder deutlich enger. Der Versuch wird noch 2 mal mit dem gleichen Effect fortgesetzt, dabei wird das Thier sehr unruhig. Die Pupillen erweitern sich stets maximal. Als der Reiz zu lange fortgesetzt wird (2-3 Minuten), stirbt das Thier unter allgemeinen. Convulsionen. Die Section ergiebt ganz die gleiche Hyperaemie des Rückenmarks wie neulich. Im Moment des Todes waren die Retinalgefässe wieder sehr eng geworden.

Wir haben noch bei zwei Kaninchen durch faradische Reizung des blossgelegten Rückenmarks Erweiterung der Retinalgefăsse erzielt - es ergab sich dabei nichts Neues, so dass wir die Versuche nicht im Detail aufuführen brauchen. Dass wir uns mit diesem allgemeinen Resultat zufrieden gaben und von vornherein vollständig auf den Versuch verzichteten, näher zu bestimmen, von welchen Theilen des Rückenmarks aus die Reizung überhaupt oder wenigstens am Meisten wirksam war, wird Derjenige leicht begreifen, der sich die grossen technischen Schwierigkeiten dieser Untersuchung vergegenwärtigt, wo der Ophthalmoskopie wegen im ganz verdunkelten Raum operirt und auch für die Lage des Thiers nur die für die Ophthalmoskopie günstigste gewählt werden muss, in der es dann oft für den andern im Dunkel arbeitenden Experimentator schwer genug ist, anch nur das Rückenmark überhaupt isolirt zu treffen. Selbst für die Bestimmung der Reizstellen im Verhältniss zur Längenausdehnung des Rückenmarks können wir nur die approximatiye Angabe machen, dass, wenn das Brustmark zum Theil frei lag, die Reizung immer desto wirksamer schien, je mehr nach oben die Electorden angesetzt wurden, möchten aber diesen Punkt noch sehr erneuter Specialuntersuchung empfehlen. 
Beim Frosch zeigte sich Folgendes:

Es wurden zwei Nadelelectroden in die unterste Partie des Rückenmarks eingestochen und ein schwacher Inductionsstrom durchgeleitet, während die eine Electrode $5 \mathrm{~mm}$ über der andern stand. Dabei wird unausgesetzt der Kreislauf in der Hyaloidea beobachtet. Nach Schliessung des Stroms wird 2 mal eine Verlangsamung des Blutstroms bis zu fast völligem Stillstand desselben beobachtet. Nur wird das Rückenmark etwas weiter oben durchschnitten. Es wird alsdann mit sehr schwachem Strom sowohl die unterhalb als die oberhalb des Schnitts gelegene Rückenmarkspartie gereizt und es lässt sich nun bei wiederholten Versuchen constatiren, dass die Verlangsamung des Kreislaufs nur im letzteren Fall eintritt. Eine Wirkung auf die Pupille wird dabei nie constatirt.

Nun war selbstverständlich wie oben bei der analogen Amylnitritwirkung die erste Frage, die wir uns vorlegen mussten: beruht das beobachtete Phänomen nicht auf einer Wirkung auf das Herz?

Wir machten darum den Versuch, bei Rückenmarksreizung gleichzeitig zu ophthalmoskopiren und das Herz durch ein über ihm angelegtes Fenster zu beobachten. Derselbe ist unter sehr schwierigen Verhältnissen auszuführen, indem die genaue Beobachtung des stark hyper= metropischen Froschauges schon ausserordentlich anstrengend ist und dann noch für den zweiten Beobachter die schwierige Aufgabe bleibt, in der Situation, die dem Ophthalmoskopirenden gerade am Besten passt, zugleich von hinten das Rückenmark zu reizen und von vorn das Herz zu beobachten, zudem alles im Dunkeln. So waren wir recht froh, als es uns einmal wenigstens mit Sicherheit gelang, zu constatiren, dass im Moment, wo der Kreislauf in der Hyaloidea beinahe völlig stillstand, das Herz sehlug — ob ganz ungeschwächt und in völlig gleicher Frequenz wagen wir allerdings nicht zu entscheiden. Erwägen wir aber, dass das Thier am Leben blieb und dass der Herzschlag beim Froseh, bekanntlich selbst beim 
sonst geradezu als todt zu betrachtenden noch eine grosse Zähigkeit und ungeschwächte Kraft zeigt, so dürfte doch sehr in Betracht zu ziehen sein, ob nicht direct auf die Gefässe wirkende nervöse Einflüsse das von uns beobachtete Phänomen in der Hyaloidea zu erzeugen im Stande sind, bei ungeschwächter Triebkraft des Herzens oder wenigstens bei so unwesentlicher Alteration, dass diese zur Erklärung nicht ausreicht.

Eine weitere Stätze erhält diese Auffassung durch folgendes Versuchsresultat:

Electroden direct auf das Dorsalmark eines Frosches applicirt. Stillstand der Circulation in der Hyaloidea. Ob dabei das Herz stillsteht, kann nicht entschieden werden. Nach mehrfacher Reizung sind ophthalmoskopisch Extravasate bemerkbar. Die Section des Bulbus ergiebt in der Hyaloidea bei mikroskopischer Untersuchung Blutungen, kleine um die Gefässwand sich gruppirende, theilweise mit den Gefässen verlaufende, ausserhalb der Gefässwand liegende Haufen von Blutkörperchen.

Dieser Befund wäre doch wohl jedenfalls durch eine abgeschwächte oder verlangsamte Herzaction allein nicht zu erklaren.

Der auf das Ganze der Erscheinungen gerichtete Zweck unserer Arbeit erlaubt uns auch hier nicht, lange bei der allerdings sehr verlockenden Weiterverfolgung dieser Einzelbeobachtung stehen zu bleiben. Wir müssen uns darum mit der Constatirung des Thatsächlichen in diesem Fallo begnügen und die nähere Erforschung der Bedingungen und des Mechanismus der Erscheinungen weiteren Untersuchungen vorbehalten. Sehr nahe läge $e s$, an einen Mechanismus zu denken, wie er von Cohnheim als Grundlage seiner Entzündungstheorie aufgestellt wurde Erweiterung der Gefässe, Verlangsamung des Blutstroms, schliesslich Diapedesis. Nur wäre eben der grosse Unterschied, dass Cohnheim locale Reize anwandte und in loco irritamenti beobachtete. Wenn dies auch als eine glückliche und fruchtbare Beschränkung erseheinen muss, 
so ist doch andererseits klar, dass bei der Betrachtung aller Experimente Cohnheim's und der ihm folgenden Experimentatoren, in denen auf einen Localreiz die betreffenden Phänomene in den Gefăssen auftreten, für ein weitergehendes Causalbedürfniss doch noch eine grosse Lücke im Verständniss des Mechanismus bleibt. Denn da ein derartiger Effect auf die Gefässe unmöglich rein mechanisch erklärt werden kann, wie etwa die Effecte eines Embolus, so ist der Recurs anfs Nervensystem unumgänglich: ein Weg, den die moderne Pathologie allerdings bis jetzt und wohl aus guten Gründen in bewusster und absichtlicher Einseitigkeit experimentell noch sehr wenig betreten hat. Und doch lassen sich gewiss die früher so zahlreichen neuropathologischen Entzündungstheorieen sehr gut mit den Ergebnissen der modernsten Experimentalpathologie vereinigen. Für den N. opticus und den Augenhintergrund besteht nun aber sogar darnach ein dringendes Bedürfniss. Denn wenn hier eine Entzündung durch Fermwirkung vom Rückenmark aus entsteht, so vermögen wir ja dann eben keinen Reiz in loco affectionis nachzuweisen, wie er etwa bei einer syphilitischen Neuritis durch Verschleppung reizender Producte dorthin oder bei der Stauungspapille durch den local irritirenden Einfluss der gestauten Lymphe *) stattfindet, sondern müssen hier den Angriffspunkt des pathologischen Agens in's Centrum des Reflexbogens verlegen, der auch in jenen Fällen die Auslösung der Veränderungen an den Gefässen vermittelte. Die Effecte können daun ganz die gleichen sein.

Kehren wir von dieser Abschweifung anf allgemein pathologisches Gebiet zurück zur unmittelbaren Betrachtung unserer Versuche mit Rückenmarksreizung, so sind wir weit entfernt, ihre Deutung irgendwie in einseitiger Weise

*) cfr. Kahnt, Zur Genese der Neuritis. Bericht über die 12. Versammlung der ophthalmol. Gesellschaft. Heidelberg 1879. 
zu unternehmen - es handelt sich im Gegentheil gewiss hierbei um allercomplicirteste Vorgänge.

Wenn wir erwägen, dass wir nur einmal eine unbedeutende Verengerung der Gefässe beobachtet haben und dies auch in einem der weniger beweisenden Reizversuche bei geschlossenem Wirbelkanal, so ergiebt sich als überwiegendes Resultat die Gefässerweiterung.

Eine nächste Anknüpfung hiefür ergiebt sich an Versuche von $\mathrm{Basch}^{*}$ ), der bei Splanchnicusreizung schon bestimmt angiebt, Erweiterung der Retinalgefässe gesehen zu haben. Dass es sich nun bei den von uns ausgeübten Reizversuchen um ganz ähnliche Verhältnisse gehandelt habe, ist an und für sich durchaus nicht unwahrscheinlich, und es brauchte darum gewiss noch nicht anf die in neuester Zeit besonders in Frankreich viel discutirte Frage recurrirt $\mathrm{zu}$ werden über vom Rückenmark ausgehende, dasselbe mit den vordern Wurzeln verlassende und im Halssympathicus verlaufende vasodilatatorische Fasern für die Kopfgefässe. Diese ganze Frage ist noch so unreif, und die Verfolgung der in neuester Zeit besonders zwischen Dastre und Morat einerseits, Laffont andererseits in der Pariser Société de biologie geführten Discussionen scheinen noch nicht sobald eine Einigung voraussehen zu lassen. Wir glauben also jedenfalls uns bezüglich etwaiger in diesem Sinne ausfallender Deutungen unserer Versuche äusserste Reserve auferlegen zu sollen. Das längst bekannte Schema der abdominellen Anämie, cerebralen Hyperämie und umgekehrt, das bei Splanchnicusreizungen eine so grosse Rolle spielt, würde jedenfalls vorläufig auch völlig genügen und es wäre dann in erster Linie an eine einfache Hemmungswirkung auf vasoconstrictorische, Tonus vermittelnde Nervenfasern zu denken. Ein wichtigerer Controlversuch war der, ob nicht dieselben Erscheinungen

*) Arbeiten des Leipziger physiologischen Instituts 1875. 
auch ohne jede directe Beeinflussung des Rückenmarks, überhaupt bei jeder sensiblen Reizung auftreten - es gelang uns jedoch nicht, bei starken Reizungen sensibler Nerven der Unterextremităt an den Retinalgefässen irgend eine Veränderung zu constatiren. Auch beim Frosch stellte sich die merkwürdige, oben geschilderte Circulationsstörung in der Hyaloidea, wie wir sie bei directer Rückenmarkreizung beobachteten, nie ein, wenn heftige schmerzhafte Eingriffe an der Unterextremität gemacht wurden. Dagegen ist für den Frosch $\mathrm{zu}$ bemerken, dass der Kreislauf der Hyaloidea auch in scheinbar ganz spontaner Weise oft eine sehr anffallende Verlangsamung zeigt und dass wir diesen Umstand stets sehr zu berücksichtigen hatten bei der Entscheidung, ob auch wirklich der Eingriff am Rückenmark jedesmal die bedingende Ursache war. Jedenfalls muss aber doch auch bei diesen seheinbar spontanen Circulationsänderungen an in ihren Bedingungen nicht unmittelbar nachweisbare nervöse Einflüsse gedacht werden, und ist hierfür auch die schon früher gemachte sehr hübsche Beobachtung Herrn Professor Michels bemerkenswerth, dass der Kreislauf häufig nach starkem Anblasen des Thiers mit Tabaksrauch stille stand.

War somit für die directe Rückenmarkreizung jedenfalls ein hervorragender und möglicherweise sogar specifischer Einfluss auf die Gefässe des Augenhintergrunds erwiesen, so war damit auch das für die Pathologie Wesentliche gewonnen, wobei die nähere physiologische Verfolgung des betreffenden Mechanismus, die möglicherweise noch für lange an der enormen Complicirtheit der Verhältnisse scheitern wird, nicht abgewartet $\mathrm{zu}$ werden braucht. Dass diese Wirkung gerade entgegengesetzt ist derjenigen, die durch Reizung des Halssympathicus constant zu erzielen ist, könnte zu der Annahme verleiten, es werde dieser spinale Einfluss durch andere Bahnen auf's Auge übertragen - dieser Schluss wäre aber gewiss voreilig 
in Anbetracht des absoluten Dunkels, in dem wir betreffs der hier möglicherweise in Betracht kommenden, sei es erregenden, sei es hemmenden. Innervationsvorgänge uns befinden. Im Uebrigen gälte es hier ein entscheidendes Experiment zu machen, an das wir uns jedoch vorläufig nicht wagen möchten. Wäre nümlich z. B. bei einem Kaninchen constant bei jeder Reizung eines bestimmten Rückenmarkabschnitts die geschilderte Gefässerweiterung nachgewiesen, so müsste dann vor einem Reizversuch ein Sympathicus durehschnitten werden. Ein Fortbestehen des Effects wäre alsdann entscheidend, wofern nicht eine Verbindung des Sympathicus mit beiden Augen angenommen wird, wofür sich ja oben einige Anhaltspunkte ergeben haben. Bestände das Phänomen auch nach doppelseitiger Durchschneidung fort, so wäre die Frage damit natürlich entschieden; ein negatives Resultat dagegen würde doch nur beweisend sein können, wenn das Phänomen vorher mit absoluter Constanz hervorzurufen gewesen wäre. Da nun aber hiervon bis jetzt in unseren Versuchen durchaus nicht die Rede sein konnte, so haben wir eben deshalb auf eine weitere Verfolgung in dieser Richtung Verzicht geleistet. In jedem Falle kann auf Grund unserer Reizversuche eine irgendwie vermittelte Beeinflussung des Gefässgebietes der Retina vom Rückenmark aus sicher angenommen werden.

Hielten wir die oben aufgeführten Falle von spinalen Verletzungen und rein spinalen akuten Fntzündungen zusammen mit unsern Ergebnissen bei faradischer Rückenmarkreizung, so konnten wir den weiteren Versuch wagen, $a b$ es uns nicht gelingen würde, durch experimentelle Rückenmarksläsionen pathologische Veränderungen am Opticus zu erzeugen. Zuerst wurde blos der Versuch gemacht, ob grobe Erschütterungen der Wirbelsäule einen ophthalmoskopisch sichtbaren Effekt zeigen würden: - es wurden mit einem Metallhammer länger fortgesetzte starke 
Schläge auf den Rücken des unverletzten Thiers geführt. Das Resultat war jedesmal ein rein negatives. Es lässt sich dasselbe, beiläufig bemerkt, auch noch verwerthen mit Rücksicht auf unsere oben angeführten ebenfalls negativen Experimente über den Einfluss der sensiblen Reizung.

Ebenso fielen alle Versuche durch galvanocaustisch verursachte Rückenmarksläsionen an Katzen Opticusaffectionen zu erzeugen, negativ aus, obwohl die Thiere die nur wenige Secunden dauernde Operation zum Theil mehr als eine Woche überlebten.

Wir waren durch das negative Resultat dieser Versuche keineswegs überrascht, da es ja bisher beim Thier noch nicht einmal gelungen war, auf viel directere Weise Neuritis optica zu erzeugen.

Die Richtigkeit der Annahme, dass das Experiment einmal gelingen muss, wofern es überhaupt beim Thier eine Neuritis optica giebt, besitzt eine gewisse unleugbare Evidenz; ob aber diese Voraussetzung richtig ist und die Läsion welcher Rückenmarkstheile dann in erster Linie in Betracht käme, darüber könnten erst unzählige Versuche entscheiden, bei denen ein positives Resultat mehr Werth hätte als hundert negative.

Auch von klinischer Seite aus werden wir in Betreff der Localisation im Rückenmark vorderhand nicht, weiter kommen. Wenn auch rerschiedene unter den oben angeführten Fallen, was die Localisation in der Längsaxe betrifft, durch ihre übrigen Symptome keinen Anlass gäben, sie über das Lendenmark hinauf zu verlegen, so kam doch fur die gerade die Irisinnervation oder den Opticus betreffende Störung eine weiter nach oben sich erstreckende Localisation vorläufig keineswegs sicher ausgeschlossen werden. Und dasselbe gilt für die Localisation auf dem Querschnitt. Allerdings macht es den. Eindruck, als ob Pupillenstarre, Opticus - und Augenmuskelaffection vorzüglich bei den Füllen vorkommen, in denen ausserdem v. Graefe's Archiv für Ophthalmologie. XXVII. 3. 
sicher auf die Hinterstrünge zu beziehende Symptome vorhanden sind, z.B. Fehlen des Patellarreflexes und Neuralgien. Nichts häufger als Fälle, in denen diese Combination in einem recht frühen Stadium der Erkrankung noch ganz allein für sich besteht. Die von uns oben wiedergegebenen Krankengeschichten, in denen sich die Opticusaffection zum Symptomenbild der spastischen Spinalparalyse, also mit grösster Wahrscheinlichkeit einer Erkrankung der Seitenstränge $z u$ gesellen schien, dürften in dieser Richtung durchaus nicht eindeutig sein, da bei der immer mehr sich aufdrängenden Thatsache der Häufigkeit combinirter Systemerkrankungen im Rückenmark, die Opticusaffection auch schon früh auftretende Theilerscheinung einer sonst noch maskirten Erkrankung der Hinterstränge sein könnte. Ausserdem hatte jener erste Fall auch unter mehr acut myelitischen, auf ein Ergriffensein des Querschnitts in grösserer Ausdehnung deutenden Erscheinungen eingesetzt.

Wir wenden uns nun zu der gesonderten Betrachtung der drei Bestandtheile der Symptomengruppe, die wir als spinale Trias am Auge bezeichnen können.

\section{Opticus.}

Unter einer spinalen Opticuserkrankung verstehen wir eine solche, die in directer Abhängigkeit von primär erkrankten, vorderhand jedoch noch keineswegs genauer zu bestimmenden, wahrseheinlich räumlich nicht concentrirten. Rückenmarksstellen ans auf dem Wege einer vasomotorischen Innervationsstörung za Stande kommt. Dieselbe kann acut oder chronisch auftreten und im ersteren Fall ubergehen entweder in Heilung oder in ein chronisches Stadium. Letzteres tritt als solches ron vornherein auf in Fällen chronischer Rückenmarkskrankheiten, kann aber in seinem fruheren Verlanf unter dem Bilde acuter Nachschübe auftretende Erscheinungen bieten. Fine scharfe Scheidung 
zwischen acuten und chronischen Formen existirt überhaupt nicht. Die Bezeichnungen sind nur ein conventioneller Ausdruck für raschere oder langsamere Entwicklung. In den zahlreichen Fällen, die erst mit dem Bild einer fertigen Atrophie sich präsentiren, lässt sich manchmal aus der Anamnese ein acutes Einsetzen der Sehstörung und damit die grosse Wahrscheinlichkeit eines entzündlichen Beginns reconstruiren, in andern Fallen fehlt ein solcher Anhaltspunkt ganz und es ist für diese vorläufig die Annahme einer primären Atrophie nicht direct zu widerlegen, wie für sie zugleich die directe Abhängigkeit nicht erwiesen und blosse Gleichzeitigkeit nieht stricte ausgeschlossen werden kann. Für solche ergäbe sich dann, würde der ganze Befund im speciellen Falle gegen ein directes Abhängigkeitsverhältniss sprechen, zu einer ungezwungenen Erklärung der Gleichzeitigkeit als breite Basis die bei solchen Kranken sich so häufig findende allgemeine Frnährungsstörung in den Arterien des Centralnervensystems, die atheromatöse Entartung, auf der gewiss auch in vielen Fällen die Combination von Hirnparalyse mit der spinalen Erkrankung beruht. In noch andern aber ist die chronische Entzundung in ihrem Uebergang zur Atrophie direct von Woche zu Woche zu beobachiten.

Von dem Begriff der spinalen Opticusaffection sehliessen wir aus die Fälle, in denen nachweisbar das gesammte Centralnervensystem in diffuser Weise ergriffen ist, wie bei der sogenannten multiplen Solerose des Hirns und Rückenmarks. Hier lässt sich erstens einmal die directe Abhăngigkeit von der spinalen Erkrankung durchaus nicht beweisen, da eine völlig selbstständige Localisirung der chronisch entzündlichen Processe wie iiberall, so auch im Nervus opticus stattfinden kann. Zweitens lässt sich pathologischanatomisch besonders aus einem Präparat der Sammlung des Herrn Prof. Michel, herstammend von einem Fall mit multiplen sclerotischen Herden sehr leicht die Ueber- 
zeugung gewinnen, dass es auch im Sehnerven einen Process mit disseminirten, erkrankten Stellen giebt, der von dem continuirlich fortschreitenden bei rein spinalen Erkrankungen wohl zu trennen ist. Dagegen bleibt der spinalen Erkrankung ihre causale Bedeutung bei Opticuserkrankungen im Zusammenhang mit der ausserordentlich häufig sich findenden Combination ron Leptomeningitis chronica mit chronisch-myelitischen Processen, d. h. klinisch ausgedrückt bei Paralytikern mit spinalen Symptomen. Wie wir schon Eingangs erwähnten, war gerade die Thatsache, dass unter unsern zahlreichen Paralytikern immer nur diejenigen Sehnervenerkrankungen zeigten, bei welchen eine gleichzeitige Localisation des Krankheitsprocesses im Rückenmark sich diagnosticiren liess, für uns ein hauptsächlicher Anlass, an den rein spinalen Ursprung in allen Fällen zu denken.

Wieder ein auderer Fall liegt jedoch vor, wenn bei einem Hirnkranken, mag er nun spinale Symptome bieten oder nicht, eine rein durch die Sehnervenscheiden vermittelte Fortpflanzung meningealer Processe an der Basis stattfindet. Fur die Paralytiker speciell ist jedoch zu bemerken, dass diese offenbar durchaus nicht sehr häufig ist, was sebr gut im Einklang steht mit dem bekannten Sectionsbefund der Paralyse, wo im Gegensatz zu hochgradigsten Veränderungen an der Convexität die Pia und Rinde der Basis völlig intact sein kann.

Ausserdem sei noch an die Pachymeningitis der Convexität erinnert, die als mehr accidentelle Complication auch der progressiven Paralyse natürlich wieder ihrerseits die für sie charakteristischen Veränderungen setzen kann.

Die differentialdiagnostischen Momente des ophthalmoskopischen Befundes für Spinalaffectionen in unserem Sinne sind etwa folgende:

Geht man vom neuritischen Stadium ans, so kann man für dieses aus dem ophthalmoskopischen Befund allein 
nur schwer eine Differentialdiagnose stellen. Zwei Falle, wovon der eine durch eine spinale Erkrankung inducirt ist, der andere in Verbindung mit einer Erkrankung der Hirnmeningen steht, können, wofern bei beiden in einem gegebenen Zeitpunkt keine Zeichen von Atrophie vorliegen, sich im Augenspiegelbild vollkommen gleichen. Bei wieder * holter aufmerksamer Beobachtung wird differentiell diagnostisch der Umstand ins Gewicht fallen, dass bei den in Rede stehenden meningealen Affectionen die entzündlichen Erscheinungen sich im höheren Maasse entwickeln im Vergleich $z u$ den spinalen. In der Mehrzahl der Falle tritt bei der spinalen Neuritis die capilläre Hyperämie wie die der gröberen Gefässe in den Vordergrund, während die Schwellungssymptome zurücktreten. Die Conturen des Opticus sind meist glatt, scharf oder können doch nur sehr wenig verwaschen sich zeigen. Der Entzündungsvorgang grenzt sich auf der Papille meist vollkommen ab und lässt die peripapilläre Zone der Retina, welche sonst häufig durch den Augenspiegel als im Entzündungsgebiet eingeschlossen erscheint, fast immer frei. Häufig sieht man neben einer Verbreiterung der Arterien in der Füllung der Venen eine Ungleichmässigkeit. Der Durehmessèr dieser Gefässe scheint in den einzelnen Ausbreitungsbezirken bald leicht erweitert, bald wieder enger, woraus eine verschiedene Farbennuancirung der Blutsäule resultirt. In praxi gestaltet sich die Sache dadurch einfacher, dass bei den spinalen Processen sich fast ansnahmslos neben entzündlich gereizten Partien des Sehnervengewebes schon atrophisch verfärbte finden, und damit ergeben sich sichere differentiell diagnostische Anhaltspunkte.

Denn das Bild der spinalen Atrophie ist gegenüber der auf irgendwelcher anderen aetiologischen Basis beruhenden gekennzeichnet durch die characteristischen Farbenerscheinungen des Opticusgewebes, die sich rom lichten Weissgrau bis zum tiefen Gran bewegen. Besonders 
ins Gewicht fallend wird hierfür die Untersuchung bei guter Tagesbelenchtung. Oft bei künstlicher Beleuchtung durchans nicht nachweisbare Farbenverschiedenheiten erscheinen dann klar und deutlich ausgeprägt. So ist das gleichzeitige Bestehen der neuritischen und atrophischen Farbe im ersten Beginne der atrophischen Degeneration wesentlich nur durch diese Untersuchungsmethode zu bestimmen. Die Farbe des anfänglich meist in seiner temporalen Hälfte erkrankten Opticus zeigt hier einen mehr graublau bis graugrünen atrophisehen Ton und auch oft dann schon, wenn bei künstlicher Beleuchtung diese Färbung noch nicht erscheint. Die Transparenz des Sehnervengewebes ist bei spinalen Atrophien sehr bedentend, die atrophische Excavation meist sehr fruhzeitig eintretend, die Contur scharf abgegrenzt. Die Arterien sind im Stadium der ausgesprochenen Atrophie verengt, während die Venen wenig enger als normal oder auch wenig verbreitert sich zeigen, letzteres jedoch fast nie in dem Umfang, wie bei meningealer Erkrankang; Phänomene an den Gefässwandungen fehlen fast immer.

Es giebt nun aber auch ein weder spinales, noeh mit Erkrankungen der Hirnmeningen zusammenhängendes, noch als Endstadium einer Stauungspapille etc. zu fassendes ophthalmoskopisches Bild von Sehnervendegeneration, das einer solchen, die von einem die Opticusbahn betreffenden Heerd nach dem Schema der secundären Degeneration continuirlich fortgeleitet wird. Ihr ophthalmoskopisches Bild ist thatsächlich durchaus meist nicht von dem des meningealen zu trennen, sofern dieses ohne Abnormitäten an den Gefässen auftritt. Folglich trefien für dasselbe gegenüber dem der spinalen die gleichen differentiell diagnostischen Momente $\mathrm{zu}$, wie für das meningeale.

Viel mannichfaltiger gestaltet sich die Verschiedenheit der Affection bei Betrachtung der Functionsstörung. Charakteristisch bekant sind für die sog. "tabetischen 
Atrophieen" hauptsächlich die Roth-Grün-Blindheit und die sectorenförmigen Defecte der Gesichtsfeldgrenzen. Bekannt ist ferner das oft frappante Missverhältniss zwischen ophthalmoskopisehem Befund und Functionsstörungen bald in diesem, bald in jenem Sinne. Ungebührlich vernachlässigt wurden dagegen bis jetzt die subjectiven Reizerscheinungen, die ebenso den Patienten oft äusserst störend werden, wie sie von höchstem theoretischen Interesse sind. $O b$ sie bei meningealen Affectionen vorhanden sind, darüber fehlen uns bestimmte Erfahrungen. Sie liessen sich jedoch auch bei diesen viel schwerer rein deuten, da ja hier die Grundaffection immer störend concurriren würde.

Dagegen ist es doch im höchsten Grad bemerkenswerth, wenn ein mit rein spinalen Symptomen behafteter Kranker, der nicht einmal einen Augenblick Kopfweh hatte, fortwährend von ausgesprochenen subjectiven lichterscheinungen gequalt wird. Als ein höchst instruetives Beispiel dieser Art führen wir folgenden Fall an:

Ein Patient mit Verlust der Patellarsehnenreflexe, früher lancinirenden Schmerzen in den Beinen, jetzt Ameisenkriechen and Taubheitsgefühl im Gebiet des L. nerv. ulnaris und reflectorischer Pupillenstarre ist durch Optieusatrophie beinahe amaurotisch. Dabei ist eine solche Lichtschen vorhanden, dass er uberhaupt in einem nicht verdunkelten Raum es nur mit sehr dunkeln Gläsern ohne die lebhaftesten Beschwerden aushalten kann; diese Beschwerden bestehen in einem beständigen Funkensehen und Scheinbewegungen der Objecte. Besonders aber Nachts hat er viel über subjective Lichterscheinungen zu klagen. Er sieht an der Tapete dunkle Gestalten sich bewegen - sagt, er könne jetzt begreifen, wie Lente meinen können, Gespenster zu sehen. Wonn er abergläubisch wäre, würde er jetzt auch daran glauben. -

Charcot pflegt in seinen klinischen Besprechungen von in allererstem Beginn stehenden Tabesfällen grossen Nachdruck auf die nach aussen offene Mauerzacke zu. 
legen, die er sehr häufig bei seinen zahlreichen Kranken gefunden hat.

Die Analogie mit der Amaurosis partialis fugax ist hier schlagend und beiläufig dürfte daraus auch ein starker Beweis für die innere Verwandtschaft der beiden Processe zu entnehmen sein. Die letztere ist zweifellos ein durch die Bahnen des Sympathicus vermittelter Bestandtheil eines Migraineanfalls. Es ist nun gewiss ron höchstem Interesse, dem gleichen Symptom das einemal bei einer rein functionellen Nervenkrankheit, das andere Mal bei destructiven Rückenmarksprocessen zu begegnen, gerade wie wir für die neuralgischen Reizerscheinungen das gleiche Verhältniss finden, hier eine rein functionelle Ischias, dort die Neuralgieen im Ischiadicus des Tabetikers. Bei der oben erwähnten descendirenden secundären Degeneration kommen diese Reizerscheinungen sicher nicht vor.

Wir wollen bei diesem Anlass zuruckkommen auf den von Mooren ausgesprochenen, oben auf $\mathrm{S} .126$ angeführten Gedanken. Es handelt sich dabei auch in letzter Instanz um die Unterscheidung zwischen einer functionellen und matesiellen Neurose. Letztere wäre in den Fällen, die Mooren im Auge hat, da vorhanden, wo die Brïcke zwischen der Affection der Sexualorgane und des N. opticus durch eine anatomisch nachweisbare Rückenmarkskrankheit geschlagen war. Auch hier drängt sich die Analogie mit dem M. Basedowi auf und es sei besonders an den gewissermassen berühmten Fall von Förster (Handbuch der Augenheilkunde von Graefe-Sämisch VIL. S. 97) erinnert von Exophthalmus nach starker sexneller Ueberreizung, womit dann andererseits wohl wieder auf's Innigste zusammenhängt der oft so evidente Einfluss, den Gravidität und Puerperium anf einen bestehenden M. Basedowi in günstigem Sinne äussern. Ganz in die gleiche Kategorie Fon Frscheinungen gehören nun auch die in unzweideutigem Zusammenhang mit Vorgängen in den Sexualorganen des 
Weibes stehenden Opticusbefunde. Wenn nun auch die hier in Betracht kommenden Bahnen sicher durchs Rückenmark führen, so sind solche Individuen doch nicht rückenmarkskrank und diese Erkrankungen wären insofern als functionelle zu bezeichnen, weil sich im Centralnervensystem kein materieller Erkrankungsherd nachweisen lässt, ein solcher vielmehr entweder gar nicht oder nur in entfernten Organen gefunden werden kann, von wo aus er Fernwirkungen ausübt. Mooren denkt bei den in Rede stehenden Amaurosen und Amblyopieen rorzugsweise an Circnlationsstörungen im 0ccipitalhirn - es müssten dann aber jedenfalls diese cerebralen Amaurosen, wenn solche überhaupt in dieser Weise zu Stande kommen, streng geschieden werden von den peripheren, als deren Paradigma der Fall Samelsohns (Centralblatt für Augenheilkunde 1881, S. 200) gelten kann, bei dem als sichtbare Grundlage der einseitigen Störung abnorm enge Gefässe gefunden wurden, die sich dann auf Amylnitrit erweiterten.*) Sie von jener cerebralen zu scheiden, dazu könnte dann neben dem dort negativen, hier positiven ophthalmoskopischen Befund als weiteres differential-diagnostisches Hilfsmittel die Pupillenreaction herbeigezogen werden, die ceteris paribus bei cerebraler Amaurose erhalten, bei peri-

*) Wie hier das Abnorme Gefässverengerung war, so ist es dann, wie wir gesehen haben, in den meisten andern Fällen Erweiterung. Ueber diesen nur scheinbaren Widerspruch kommt man am raschesten ins Klare durch die Betrachtung des wichtigen Falls, den Chaxcot mittheilt (Vorträge über Krankheiten des Nervensystems. Deutsch von Fetzer. Stuttgart 1874, Bd. 1. S. 367), in dem nach Galezowsky's Diagnose "ohne Zweifel alle Störungen auf spasmodische Contraction der Arterien an einzelnen. Stellen und atf ihre Dilatation an andern zurïckzaführen waren." Ausserdem sei noch nachdrücklich dorthin verwiesen wegen der gerade für unsern Gegenstand sehr wichtigen Auseinandersetzungen Charcots über den Uebergang einer functionellen Nervenkrankheit in eine materielle. 
pherer aufgehoben wäre, wie es eben bei Samelsohn der Fall war.

Kehren wir nach dieser Abschweifung zurück zu der Differentialdiagnose spinaler Opticusaffectionen. Die charakteristischen Gesichtsfelddefecte finden ihre genügende Frklärung in entsprechenden ophthalmoskopischen Befunden, jedoch nur dann, wenn es sich um einen sehr ausgeprägten peripheren Ausfall handeln sollte, während noch vollkommen normale centrale Sehschärfe besteht. Hier kann man häufig constatiren, dass dem Gesichtsfelddefect ophthalmoskopisch eine atrophische Stelle der Papille entspricht. Dagegen wäre in Fällen von ophthalmoskopisch nachweisbarer gleichmässig weit vorgeschrittener Atrophie ein, trotz der hier anzunehmenden gleichmässigen Erkrankung der zur Macula und zur Peripherie gehenden Fasern bestehendes Missverhältniss zu Gunsten der centralen Sehschärfe einfach durch die viel bessere Chancen bietende feinere Versorgung der Fovea centralis zu erklären. Es bestände also aus diesem Grunde in der Peripherie ein für unsere perimetrische Messungen schon absolut scheinender Defect, der bei photoperimetrischer möglicherweise viel weniger markirt exscheinen dürfte. Dass bei der Aufnahme des Gesichtsfeldes Schwankungen vorkommen, ergiebt sich aus einem unserer Falle, wo wiederholte Aufnahme des Gesichtsfeldes Veränderungen in den Grenzen desselben ergab. Andererseits giebt es aber auch Fälle exquisiter spinaler Atrophie mit völlig intactem Gesichtsfeld. Folglich lässt sich in differential-diagnostischer Beziehung ein in dieser Richtung negativer Befund nie verwerthen. Endlich sind noch die, wenn auch seltenen Fälle zu erwähnen von völlig intactem Gesichtsfeld bei hochgradiger Herabsetzung der centralen Sehschärfe. Es muss für sie anatomisch die umgekehrte Deutung von der für die obige Funktionsstörung angenommenen gelten. Als ein solcher sei unser obiger (S. 116) erwähnt. 
Es findet sich also innerhalb der spinalen Optiouserkrankungen ein charakteristischer Gegensatz einerseits zwischen Einschränkung des peripheren Gesichtsfeldes und

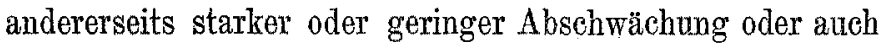
Erhaltensein der centralen Sehschärfe, während bei meningealer Atrophie sich das ganze Gesichtsfeld in gröberer Weise gestört und ohne solche charakterist ische Defecte zeigt, welche, wenn vorhanden, einen hohen differentialdiagnostischen Werth gewimnen. Bei der descendirenden Atrophie finden sie sich ebenfalls nicht.

In der Störung der Farbenperception bei Spinalerkrankungen stellt die Natur schlagende Experimente an, die als die wichtigste Erkenntnissquelle für die Farbenlehre betrachtet werden müssen. Die Beobachtungen an unserem Krankenmaterial stützen auch den Satz, dass Farbenstörungen unverhältnissmässig häufig sind bei spinalen Processen, und dass, wo solche vorhanden, RothGrün Blindheit der weitaus überwiegende Befund ist. Sie ist bei der spinalen Atrophie in jedem Fall von Farbenstörung vorhanden, kann sich aber durch Hinzutreten von BlauGelbblindheit zu totaler Farbenblindheit ergänzen. Der Satz: wer Rothblind, ist auch Grünblind, gilt im Allgemeinen, aber nicht mit derselben Absolutheit wie für den angeborenen Daltonismus; denn es ist sehr wohl zu bemerken, dass es sich beim Daltonismus nicht um eine Entwicklung und nicht um ein Gewordenes handelt, sondern dass der Daltonist nie die Vorstellung Grün und Roth gehabt hat, während der spinale Atrophiker, der selbstverständlich die betreffenden Farbenvorstellungen in seinen Erinnerungsbildern sich mit voller Schärfe bewahrt, der von der Aussenwelt ihm gelieferten Empfindungen allmählich und stückweise verlustig goht. Es rommt z. B. ein Patient, der heate eine leichte Herabsetzung der Perception für Grün, sonst noch völlig intacte Farbenempfindung hat, nach 14 Tagen wieder mit einem nun auch die Roth- 
empfindung betreffenden Defect. Der Kranke ist aber durehaus nicht in der Weise roth-grünblind geworden, dass in einem gegebenen Moment jeweils dem Defect auf der Seite des Roth einer auf der Seite des Grün entspräche. Stufenweis, allmählich, partiell ist auch der Verlust innerhalb einer einzelnen Farbe, und um hieraus den möglichsten Gewinn zu ziehen, sind besonders wichtig die subjectiven Wahrnehmungen intelligenter Patienten.

So wurde uns ron einem solchen in einer gewissen Periode seines Leidens stets die bestimmte Angabe gemacht, dass er die dunkeln Nuancen von Grün noch in früherer Deutlichkeit vollkommen als Grün erkenne, während er in Hellgrün nur Gelb zu sehen vermöge. Er brachte öfters dunkle Baumblätter mit und demonstrirte, wie ihm die dunklere Oberseite derselben grün, die otwas hellere Unterseite rein gelb erscheine. Das Hellgrün im Unterfutter seines Sonnenschirms erschien ihm so evident gelb, dass er zu Beginn seiner Erkrankung, als or noch keine Ahnung von seiner Farbenblindheit hatte, wegen dieser Differenz mit dem Verkäufer des Schirms einen grossen Scandal bekam. Patient war desto befähigter zu einem Urtheil über Farben, da er Modewaarenhändler ist. Gewisse Farben wurden ihm geradezu unangenehm und es zeigte sich die Hyperästhesie, die wir für gewisse Stadien des Processes dem Licht überhaupt gegenüber hervorheben müssen, bei jhm z. B. eine Zeitlang für Hellblau, so dass or positiv versicherte, or habe jedesmal wegsehen müssen, wenn er einer hellblauen bayrischen Uniform begegnet sei. Später sei dies dann wieder ganz verschwunden. So wunderbar die Angaben klingen, so darf doch bei der absoluten Glaubwürdigkeit des Individuums, das sich auch sonst ganz gut selbst beobachtete, nicht daran gezweifelt werden. Ein anderer Patient, akademisch, speciell naturwissenschaftlich gebildet, suchte sich immer, weil er ihre sehlechte prognostische Bedentung kannte, seine Farbensinnstörung selbst zu dissimuliren - liess man ihn nun auf dem Glauben, so gab er ganz constant, aber auch ohne jedes Zögern - Grün für Roth und vice versa an und glaubte damit das Richtige getroffen zu haben. Wie deutlich: ist hier wieder der Unterschied rom angeborenen Daltonisten, 
der eben einfach von den betreffenden Farben überhaupt nie etwas gesehen hat!

Dass Angesichts solcher Thatsachen, die doch dem Ophthalmologen alltäglich begegnen müssen, die Dreifasertheorie noch aufrecht erhalten werden konnte, könnte fast unbegreiflich erscheinen. Erklärlicher erscheint es freilich, wenn man bedenkt, wie wenig die Physiologie besonders in Deutschland von pathologischen Thatsachen Notiz zu nehmen pflegt. In der Farbenlehre wurde im besten Fall auf den angebornen Daltonismus Rücksicht genommen, von dem aber weniger zu holen ist als von Fällen erworbener Farbenstörung.

Versuchen wir einen Augenblick nur, uns auf den Boden dieser Theorie zu stellen, so hätten wir, ganz abgesehen von der Unerklärbarkeit des Factums der paarweisen Störung bei einem Roth-Grün-Blindgewordenen ganz ruhig die Consequenz hinzunehmen, dass die grobe entzündlich atrophisehe Erkrankung sich gerade nur die betreffenden Fasern herausgesucht hätte. Wer den Process am Opticus kennt, wird mit uns diese Vorstellung als monströs erklären und uns erlassen, sie noch im Detail ad absurdum zu führen.

Ernsthafterweise kann es sich bei der erworbenen Farbenstörung überhaupt nur um drei Moglichkeiten handeln. Erstens könnte man für gewisse Fälle den Sitz der sie bedingenden krankhaften Störung ins Centrum, in eine Hirnparthie, verlegen. Für die uns beschäftigenden Fälle aber, in denen bemerkenswerther Weise Farbenstörungen gerade sehr hänfig sind, lüsst sich diese Annahme wohl direct ausschliessen dadurch, dass wir gerade für sie doch bisher mit grosser Wahrscheinlichkeit die Abhängigkeit von cerebralen Heerden ausgeschlossen haben. Dass bei der Stauungsneuritis eines Gehirntumors Farbenstörungen auch auftreten können, beweist selbstverständlich nichts für cerebrale Localisation, da es sich hierbei ja auch nicht um 
ein Heerdsymptom handelt. Im Allgemeinen bleiben aber anerkanntermassen die Farbenstörungen den spinalen Processen fast pathognostisch. Einer solchen Erklärung zu Liebe müsste auch hier ad hoc eine sonst durch gar nichts bewiesene intracerebrale Erkrankung angenommen werden. Umsomehr würde aber hier ignotum per ignotius erklärt als die einzige Farbenstörung, die möglicherweise cerebral zu localisiren ist, die hysterische, nach den sehr bestimmten Angaben Charcot's and seiner Schüler sehr deutlich von der spinalen differirt.*) Während bei letzterer die Störung sehr wesentlich darin besteht, dass beständig Farben verwechselt werden, dass Täuschungen, Irrthümer vorkommen, Grün als Gelb, wie wir oben anführten, bezeichnet wird, sieht die Hysterische alle Gegenstände, die dem normalen Auge in der ketreffenden Farbe erscheinen, wenn sie vorübergehend oder danernd für diese eine Empfindungslähmung zeigt, einfach Grau, ohne dabei die mindeste Vorstellung von Farben zu haben.

Bekanntlich machen die Combinationen von bestimmt localisirten Störungen anderer Sinne, sowie von cutanen Sensibilitätsstörungęn mit dieser letzteren Farbenblindheit (totale Hemianästhesie) ein hervorragendes Ergriffensein gewisser Hirnparthieen sehr wahrscheinlich und in erster linie ist hier an eine Störung im Hinterhauptslappen and der von ihm ausgehenden Projectionsbahn des hinteren Theils der inneren Kapsel zu denken. Als von diesen Regionen ausgehend, kennen wir nun aber mit grösserer Sicherheit völlige Amaurose. Ihr klarstes Beispiel ist die corticale Hemiopie, in deren absolut amaurotischem Bezirk eine Farbenstörung natürlich durchaus keine Stelle findet.

*) Vergl. Richer, études eliniques sur l'hystéro-épilepsie. Paris 1881. S. 582, wo sich übrigens der Begriff Daltonismus missbränchlicher Weise offenbar auch auf Untersuchungsresultate bei erworbener Farbenblindheit bezieht, die man streng trennen sollte. 
Wollten wir uns aber die Localisation einer Farbenstörung, wie es die uns beschäftigende ist, in der Hirnrinde ansehaulich vorzustellen versuchen, so müssten wir dabei nicht nur aller empirischen Anhaltspunkte entbehren, sondern würden anch a priori den allergrössten Schwierigkeiten dabei begegnen, für jede Farbe nun eine räumliche Anordnung auszudenken, in welcher die sie percipirenden Elemente isolirt betroffen wären.

Es würde somit nach allen der Erklärungsversuch durch eine cerebrale Erkrankung durchaus das Verständniss nicht erleichtern, sondern wir können es auch für das hier in Rede stehende Problem nur als eine glückliche Vereinfachung bezeichnen, wenn der Erkrankungsprocess wirklich auf die Partien beschränkt werden kann, wo ex notorisch nachgewiesen ist - auf den Nervus opticus selbst mit mehr oder weniger vorgeschrittener centripetaler Progression. Und dies ist eben die zweite und wahrscheinlichste unter den drei möglichen Annahmen, diejenige, die allein den Vorzug eines nachgewiesenen materiellen Substrates besitzt. Abgesehen hiervon aber dürfte die Entscheidung zwischen ihr und einer dritten, die die Farbenstörung in den Netzhautelementen localisirte, doch noch in Betracht kommen, da von vornherein durchaus nicht in Abrede gestellt werden kann, dass die Bedingungen für eine derartige Störung in den Sehelementen der Retina gewiss ebenso gut gegeben wären, wie für die der gröberen Elemente, der Nervenfasern, und da andererseits bei der enormen Feinheit des Objects aus der Thatsache, dass bis jetzt histologisch nichts Pathologisches in den feinsten Sehichten der Retina nachgewiesen worden ist, nichts gefolgert werden darf. Allein die Thatsache, dass gerade bei den Erkrankungen des Sehnerven Farbenstörungen im Vergleich zu denen der Retina zum mindesten ausserordentlich viel häufiger sind, giebt doch zu denken, und muss uns veranlassen, wu fragen, 
ob nicht die Farbenstörungen doch sich erklären liessen allein aus der nun einmal einzig sicheren Thatsache der Leitungsstörung. Fin erster gewichtiger Einwand gegen diesen Versuch liesse sich erheben durch den Hinweis auf den Mangel an Farbenstörung sowohl bei vielen hochgradigen spinalen als dann ganz besonders fast ausnahmslos bei den übrigen nicht spinalen Sehnervenerkrankungen. So schwerwiegend dieser Einwand erscheinen kann, so muss man sich ihm gegenüber doch vor allem auf den festen Boden der Thatsache stellen, dass bei den in Rede stehenden Erkrankungen das Missverhältniss zwischen materiellem Befund und Funktionsstörung nach allen Richtungen überhaupt ein sehr starkes sein kann, wie dies schon oben für das Verhältniss des centralen zum peripheren Sehen dargethan wurde. Von diesem Gesichtspunkte aus muss aber jedenfalls auch für anseheinend ganz gleich ophthalmoskopische Befunde die. Möglichkeit einer grössern Variabilität auf der functionellen Seite auch für die Leitung der Farbenempfindung zugegeben werden. Nun gewinnt eine solche Betrachtungsweise eine weitere bedeutende Stütze darin, dass in den Störungen der cutanen sensibeln Nerven sich schlagende Analogien finden. Wir erinnern nur an die reichen Variationen, die Sensibilitätsstörungen bei Erkrankungen anderer Nervenbahnen bieten können, wie die Leitungsstörung für Temperatur, Schmerzund tactile Eindrücke durchaus nicht proportional zu sein braucht. Speciell für die Tast- und Temperatureindrücke ist ja das Missverhältniss so gross, dass schon manche sich dadurch veranlasst sahen, eigene Tast- und Temperaturnerven anzunehmen. Solche existiren aber gewiss so wenig als der Opticus eigene Farbensinn- und eigene Formsinnfasern hat, vielmehr darf wohl vorderhand als wahrscheinlichste Vermuthung die aufgestellt werden, dass das Verhältniss des allgemeinen Raumsinns in Haut und Auge zu den speciellen Modalitäten der Temperatur- und Farben- 
empfindung das gleiche ist. Hier wie dort hätten wir dann verschiedene Vorgänge in peripheren Endapparaten, die durch die gleichen Nervenfasern zum Centrum geleitet werden, normaliter vollkommen und distinet, in kranken Nerven mangelhaft und confus.

Gerade für pathologische Fälle erscheint der von Preyer*) neuerdings zuerst gemachte Versuch, eine Analogie zwischen Farben- und Temperaturempindung zu statuiren, äusserst fruchtbar und diese Betrachtungsweise, die Preyer gegenwärtig erst auf Fälle von Daltonismus stützte, wird gewiss in kürzester Zeit auch aus der eigentlichen Pathologie kräftige Stützen erhalten.

Am ungezwungensten erscheint die Annahme, dass für die Farbenperception allmählich sich steigernde Leitungserschwerungen das störende Moment abgeben, auch für unseren obigen Fall, der bezüglich des Farbensinns noch folgende bemerkenswerthe leichte Störung bot (S. 117). Während nämlich bei jener Patientin der Farbensinn nach Prüfung mittelst Holmgreenscher Methode als absolut intakt erscheinen musste, zeigte sie auf Vorlegung der Stilling'schen Tafeln bei späteren Untersuchungen das merkwürdige Verhalten, dass sie, aufgefordert, die aus rothen Quadraten zusammengesetzten Buchstaben anzugeben resp. die Figuren mit dem Finger zu verfolgen, immer erst ziemlich lange Zeit branchte, bis ihr dies gelang, während sie es für alle übrigen Farben stets augenblioklich im Stande war. Die ganz willige und anstellige Patientin gab dabei auch jedesmal an, hier einige Schwierigkeit zu empfinden und erst nach einiger Anstrengung die dureh die rothen Quadrate bezeichneten Linien zu entdecken.

*) Farben - und Temperatursinn ete. Pllüger's Arehiv, Bd. XXV. S. 31.

v. Graefe's Archiv für Ophthalmologie, XXVII. 3. 
Diese kaum angedeutete Farbenstörung lässt sich ungezwungen doch nur dadurch erklären, dass Hindernisse auf der Leitungsbahn liegen, die nur durch längere Einwirkung des Reizes, durch Summirung von Reizanstössen überwunden werden.

Nach dieser Erklärung gingen also die chemischen Vorgänge der Retina nach wie vor normal von Statten, im Centrum wäre noch Perceptionsmöglichkeit vorbanden, wie ja auch nach den Angaben der intelligenten Patienten die Farbenerinnerungsbilder in voller Schärfe erhalten sind; aber die defecte Leitung übermittelt die Vorgänge in der Retina confus ins Centrum.

\section{Pupille.}

Das Problem der reflectorischen Pupillenstarre bei Spinalkrankheiten wurde im vorigen Jahre von $\mathrm{Erb}^{*}$ ) dahin präcisirt, dass der Ort der Störung in einem Reflexbogen zwischen Opticus und Oculomotorius zu suchen sei, indem jeder der beiden Nerven für sich ja intact functioniren kann, ersterer ausweislich seines überhaupt normalen Befundes, letzterer wegen seiner erhaltenen Function bei Convergenzbewegung. Es fragt sich nun, ob diese Annahme in dem Sinne die einzig mögliche ist, dass auf einen im Hirn, also z. B. in der Vierhügelgegend, liegenden Erkrankungsheerd recurrirt werden müsste. Da dies eine Durchbrechung unserer beim $\mathrm{N}$. opticus festgehaltenen Consequenz der rein spinalen Auffassungsweise involviren würde, so haben wir zuerst zu untersuchen, ob die reflectorische Pupillenstarre nicht anch ohne sie erklärbar ist. Zuerst haben wir jedoch in Anlehnung an unsere Beobachtungen die thatsächlich vorkommenden Combiuationen

*) Ueber spinale Myosis und reflectorische Pupillenstarre. Leipziger Universitätsprogramm 1880. 
von Papillenstarre mit oder ohne Myosis, von Myosis mit oder ohne Pupillenstarre kurz auseinanderzusetzen.

Die an der Pupille überhaupt möglichen Arten ihres Verhaltens sind folgende, wenn von Differenzen an beiden Angen, Unregelmässigkeiten in der Contraction und ähnlichen nicht hier in Betracht kommenden, weil wohl unzweifelhaft immer auf Hirnstörungen beruhenden Verhältnissen abgesehen wird:

a) Enge Pupillen, an denen bei Convergenzbewegung noch eine weitere minimale Verengerung nachweisbar ist, die aber in Licht und Dunkel gleich bleiben.

b) Weite oder wenigstens mittelweite Pupillen mit im Uebrigen demselben Verhalten.

c) Enge Pupillen, die im Dunkeln weiter werden, bei Lichteinfall noch enger.

d) Abnorm weite Pupillen mit demselben Verhalten.

e) Enge Pupillen, welche bei Lichteinfall noch enger, aber im Dunkeln nicht weiter werden.

Hiervon kommen bei spinalen Processen wesentlich nur in Betracht $a, b$ und e, einigermassen noch $c$, während d ganz ausserhalb der Betrachtung fällt.

Die Beweismomente, die wir gegen cerebrale Heerde bei den spinalen Opticusaffectionen ins Feld führten, gelten in gleichem Masse für die Störungen an der Pupille bei Spinalkrankheiten. Allein diese gewähren unserer Auffassung, weit entfernt ihr Schwierigkeiten in den Weg zu legen, sogar ganz nene und wesentliche Stützen. Wir können auf dem Boden der sichern physiologisehen Thatsache, dass auf die Iris fortwährend in der Bahn des Sympathicus verlaufende dilatatorische Innervationseinflüsse stattfinden, vorderhand einmal die spinale Myosis ganz ungezwungen und befriedigend erklären, wenn wir annehmen, dass Rückenmarkspartien, welche die Cebertragung dieser Innervationsvorgänge vermitteln, in die Erkrankung herein- 
gezogen wurden. In consequenter Weise ist diese Auffassung in der im rorigen Jahre erschienenen Arbeit von Rembold*) vertreten. Dass sie nicht allgemein angenommen ist, während man sie doch für die nächstliegende halten sollte, ist dadurch leicht begreiflich, dass allerdings erst erhebliche Schwierigkeiten $z \mathfrak{u}$ beseitigen sind, die ihr entgegen zu stehen scheinen.

Erstens nämlich die Thatsache, dass die enge Pupille im Schlaf, deren Ursache wohl mit Sicherheit in dem Wegfall der sensiblen Reize gesucht werden darf, auf Lichteinfall noch enger wird, während dies bekanntlich von der spinalen Myosis im Allgemeinen nicht gilt.

Zweitens die nicht mit Myosis verbundene spinale Pupillenstarre. Als durchaus nicht in Betracht kommend, müssen wir dagegen die Einwände Bessau's**) bezeichnen, der die in Rede stehende Errklärung dadurch widerlegen will, dass er einerseits bei Versuchsthieren nach Exstirpation des Ganglion supremum nie sehr starke Myosis auftreten sah, andererseits meint, dass auch am Menschen die Ferhältnisse sich so gestalten müssten, wie an seinen Versuchsthieren, wo cine gewisse Zeit nach Trennung des Sympathicus and speciell nach Exstirpation des Ganglion supremum eine schliessliche und sogar maximale Erweiterung statt der anfänglichen Verengerung erfolgte, was er als eine Folge secundärer Uegeneration des Sphincter iridis nach der Durchschneidung seiner trophischen Fasern auffasst.

Gegen den ersten Finwand ist zu sagen, dass ja sicher durchaus nicht alle Pupillenerweiternden Einflüsse durch den Halssympathicus verlaufen, während diese getrennten Bahnen sehr wohl im Rückenmark Vereinigungs-

*) Ueber Pupillarbewegung und deren Bedeutung bei den Krankheiten des Centralnervensystems. In ,Mittheilungen aus der ophth. Klinik in Tubingen" 2. Heft 1880.

**) Die Pupillenenge im Schlaf und bei Rückenmarkskrankheiten. Inauguraldissertation. Königsberg 1879. 
punkte haben können und dass ferner auch für die im Sympathicus verlaufenden die Operation sehr wohl einen Reiz setzen kann, der, wenn auch nicht so stark wie der physiologische, denselben doch bis zu einem gewissen Grade zu ersetzen im Stande wäre.

Sein zweiter Einwand berührt aber vollends den vorliegenden Gegenstand gar nicht, da er von etwas total verschiedenem hergenommen ist. Die einfache Unterscheidung zwischen einer centralen und peripheren Lähmung und ihren Consequenzen genügt schon, es klar zu machen. Auch ist ja die Thatsache, dass die spinale Myosis doch im Wesentlichen bilateral ist, genügend, um zu zeigen, dass es sich dabei um das Ergriffensein eines schon sehr complicirten coordinatorischen Apparates handelt, bei dem jedoch selbstrerständlich trotz des Wegfalls der von ihm ausgehenden Impulse die allgemein physiologischen Vorgänge nutritiver und anderer Art in der von ihm mitbenutzten Bahn des Sympathicus völlig intact sein können.

Die zwei obengenannten ernsthaften Einwände bedürfen dagegen einer genauen Analyse.

Wenn Rembold das noch Engerwerden der im Schlaf schon myotischen Pupille auf Lichteinfall mit Zuhülfenahme seiner Theorie von einem wesentlichen Einfluss der Gefässfüllung der Iris auf die Pupillenweite zu erKlären sucht, so gestattet uns allerdings der Zweck unserer Untersuchung nicht, uns ohne Weiteres für eine der Theorien der Pupillendilatation, die eines erweiternden Muskels oder die der Gefüsstheorie zu entscheiden. Wir müssen suchen überhaupt mit dem Antagonismus von Innervationskräften auszukommen. Dies ist nun offenbar für den Fall der Schlafmyosis leicht. Gerade wenn sie nur auf einer Ausschaltung der dilatatorischen Einfüsse beruht, so erklärt sich ja die Zunahme der Verengerung bei Oeffnung des Lides ganz naturgemäss durch eine nun sich hinza- 
addirende Oculomotoriuswirkung auf den Sphineter. Ganz die gleiche Betrachtung dürfte auf die physiologische, die gleichen Verhältnisse bietende Myosis des Greisenalters zutreffen. Warum ist es nun aber bei der spinalen Myosis, die nun anscheinend auch gleiche Verhalltnisse bieten würde, nicht auch so, dass die Pupille, wenn auch im Dunkeln nicht mehr weit werdend, doch auf starken Lichteinfall sich verengert? Hier ist vor Allem zu bemerken, dass es faktisch doch auch solche spinale Fälle giebt, die unserer obigen Kategorie $c$ entsprechen, Pupillen, die in der Mittellage enge, durch stärkere Belenchtung noch mehr zu verengen sind, nie aber, weder durch sensible Reize, noch durch Verdunklung zu erweitern. Dabei ist zu bemerken, dass diese Verengerung, wie wir an sehr überzeugenden Fallen zu constatiren Gelegenheit hatten, eine auffallend träge und langsame ist und dass besonders die bei Beobachtung gesunder Pupillen constant sich findenden Oseillationen immer fehlen. Dieselben scheinen uns von capitaler Wichtigkeit für die ganze Theorie der Pupilleninnervation zu sein und das besonders Charakteristische an ihnen ist die Rolle, die sie bei schroffen Uebergängen von hohen zu niederen Beleuchtungsintensitäten und umgekehrt spielen. Die Verengerung und Erweiterung schiessen jedesmal über's Ziel hinaus. Die Osoillationen wiederholen sich in stärkerer Weise oft noch ein halbdutzendmal und auch wenn ein relativer Ruhezustand, eine der neuen Beleuchtungsintensität entsprechende Mittellage eingetreten, so ist doch eine absolute Ruhe noch nicht vorhanden. So dürften denn auch die Schwankungen, die man immer bei genauer Beobachtung an der Pupille findet, nicht ausschliesslich auf anhaltende Schwankungen der Lichtintensität und der grösseren oder geringeren Convergenz der Bulbi zu sebieben sein, sondern wesentlich auch auf den nie ruhenden Wettstreit der antagonistisehen Kräfte. Aus ihm resultirt die Mittellage der Pupille, deren Be- 
rủcksichtigung unerlässlich ist. Im Schlaf ist sie z. B. eine ganz andere, bleibt aber stets hier noch durch den Antagonismus bestimmt, also physiologisch. Etwas ganz Anderes dagegen ist eine pathologische Mittellage, die wir, als aus zweierlei Störnngen resultirend, nachweisen können 1) durch dauernden Verlust der verengernden, 2) der erweiternden Kräfte.

Ad 1 kommen in Betracht Amaurose und Oculomotoriuslähmungen.

Ad 2 Ausfall der vom Rückenmark ausgehenden erweiternden Einflüsse.

Wollten wir die durch spastische Zustände herbeigeführten Verhäl,ţnisse mit berücksichtigen, so wäre natürlich für jede dieser Kategorien das Umgekehrte zu sagen. Da wir aber die spastische Mydriasis in Uebereinstimmung mit den bisherigen Autoren als eine von Reizungen der Hirnrinde ausgehende Erscheinung auffassen dürfen (klinisch vorkommend bei Hydrocephalus, Hirntumoren etc.), und da wir ferner die Möglichkeit einer solchen zwar bei Reizzuständen des Rückenmarkes theoretisch zugeben müssen, aus eigener Erfahrung aber nicht bekräftigen können, so sehen wir von ihr ab. Es muss aber grosser Nachdruck darauf gelegt werden, dass wenn sie vorkommen sollte, ihr dann das Charakteristicum der reinen reflectorischen Pupillenstarre das Erhaltensein einer Convergenzreaction nicht zukommen dürfte, da ein Spasmus nicht so leicht ïberwunden wird, und dass eben darum sie zu einer sonst vielleicht verführerisch scheinenden Erklärung der Formen von reflectorischer Pupillenstarre bei weiten Pupillen nicht unmittelbar zu verwerthen wäre. Ganz die gleiche Erwägung gilt nun aber auch für die Annahme spastischer Myosis. Fälle, in denen die Pupille auf irgend welchen Reiz noch enger wird, können wir vernünftigerweise nicht als auf Spasmus beruhend auffassen, Zur Annahme einer spastischen Myosis 
könnten wir uns nur in Fallen entschliessen, wo eine so hochgradige Pupillenenge, wie wir sie nur von der Eserinwirkung her kennen, vorhanden wäre, wo aber eben darum auch eine etwa auf einen Reiz eintretende noch stärkere Verengung, selbst wenn sie in minimaler Weise stattfände, durch unsere Hilfsmittel nicht mehr controlirbar wäre, während ja factisch die Convergenzreaction der spinalen Myosis noch eine deutliche ist. Dass eine spastische Myosis aus Reizungsvorgängen, welche durch die Oculomotorii vermittelt sind, resp. anch durch den centripetalen Theil des Reflexbogens, den Opticus, resultiren kann, wollen wir selbstverständlich nicht leugnen, dies fällt aber ausserhalb des Rahmens unserer Betrachtung. Nur in einer Beziehung konnte vielleicht jemand den Versuch machen wollen, Fälle mit spinaler Myosis in Zusammenhang mit dem Nervus opticus zu bringen. Die bäufig zu beobachtenden starken Reizerscheinungen, die wir oben besprachen, könnten zur Annahme verleiten, dass die Myosis auch einmal ein durch den Opticus veranlasstes Reizphänomen sein könnte, analog wie die starke Myosis bei Trigeminusreizung bekannt ist durch Experimente und klinische Thatsachen.

Diese Annahme entbehrt aber für spinale Fälle jeder thatsächlichen Stütze. Nicht nur wäre es ein verschwindend kleines Gebiet ron Fällen, auf welches sie anwendbar wäre, sondern speciell sprechen gegen sie auch die oben angefübrten einen spastischen Zustand überhaupt ausschliessenden Gründe. Wenn nun häufig enge und reactionslose Pupillen als besonders ominöses Symptom schwerer Hirnkrankheiten und zwar als Ausdruck eines Hirnreizes aufgefasst werden, so ist in dieser Deutung Vorsicht sehr am Platze. Die so sehr ominösen Zustände, welche man folgen sah, können in einer grossen Zahl der Falle als Erscheinungen der progressiven Paralyse gefasst werden. Nun finden sich aber bei dieser so häufig spinale Erkrankungen, die ihrerseits za spinaler Myosis führen konnen, dass anch hier ein 
zu Spasmus führender Hirnreiz erst dann angenommen werden darf, wenn das gleichzeitige Bestehen einer solchen Spinalerkrankung mit Sicherheit ausgeschlossen werden kann. Sicher wurde früher und noch jetzt in der weniger genauen Beobachtung der Irrenanstalten eine Menge Fälle spinaler Myosis auf Reizzustände des Gehirns geschoben.

Somit kommt spastische Myosis für uns nicht in Betracht wegen Mangels an Sicherheit der Beobachtung. Dagegen haben wix noch eine Moglichkeit, wie sich spastische Mydriasis mit der uns interessirenden Krankheit compliciren kann. Wenn wir nämlich für die so überaus häufige Combination von Rückenmarkskrankheiten mit Hirnparalyse uns an die experimentelle Thatsache halten, dass von der Hirnrinde aus durch Reizung starke Pupillenerweiterung erzeugt werden kann, so kann allerdings sehr wohl die Möglichkeit eintreten, dass bei einer Spinalerkrankung durch Reizung derjenigen Fasern, die von der Birninde dilatirend auf die Iris wirken, eine vom Rückenmark yanz unabbängige und alsdann sicher spastische Mydriasis entstehen kann, für die aber selbstverständlich das Criterium der mangelnden Convergenzbewegungsreaction gelten müsste. Ja, es wäre sogar nicht undenkbar, dass eine solche eine sonst bestehende Myosis maskirte, da nach Bessau's und Anderer Experimente die hier in Betracht kommenden Bahnen ganz getrennt von den anderen verlanfen. Nur führt diese Betrachtung zo der grössten Schwierigkeit in der Deutung der spinalen Myosis bezüglich der Auseinanderhaltung und Abschätzung der Stärke der von spinalen Centren aus regierten Einflusse einerseits und der vom Hirn lommenden erweiternden andererseits. Wir müssten, wenn eine solehe Trennung durchführbar wäre, eigentlich zu der Consequenz kommen, dass unter gewöhnlichen Verhältnissen dic spinalen dilatirenden Einflüsse die allein wesentlich maassgebenden sind und die cerebralen dilatirenden nur ansnahmsweise in Action treten. Dagegen würde dann wieder bei 
der Annahme einer Lähmung der erweiternden Hirnrindecentren, die durch die Frkrankung geschaffen wäre, ein weiteres im gleichen Sinn sich zum Verlust des spinalen Einflusses hinzuaddirendes Moment gegeben. Eine Berücksichtigung dieser Hirneinflüsse würde aber auch zur weiteren Consequenz für rein spinale Erkrankungen mit Myosis fuhren, dass zwar die Erweiterung auf alle möglichen peripheren Reize, deren Weg wir durchs Ruckenmark zu suchen hätten, in Wegfall gekommen wäre, dagegen auf cerebrale z. B. psychische Reize noch Êrweiterung vorhanden sein müsste. Bei der Schwierigkeit solcher Beobachtung ist es kein Wunder, wenn hierüber noch nichts sicheres Thatsächliches vorliegt.

Somit könnten wir uns nun der ausschliesslichen Betrachtung der durch Ausschaltung resp. Lähmung im weitesten Sinne von Pupillen dilatirenden Einflüssen zu Stande kommenden Verhältnisse zuwenden. Obgleich der Reflexvorgang der Papillenverengerung auf Lichteinfall in seinem centrifugalen Theil auch auf der Bahn des Oculomotorius zu Stande kommt, so ist doch die gleichfalls durch den Oculomotorius vermittelte Convergenzbewegung der Pupille streng von ihm zu scheiden. Dieser letztere Vorgang hat keine antagonistische Kraft wie jener andere, ist als eine einfache Mitbewegung aufzufassen. Es waltet also durchaus nicht das Verhältniss ob, dass bei einer möglichst starken Divergenzstellung die Pupille immer weiter würde analog dem Immerweiterwerden bei zunehmender Verdunkelung. Hierbei ist gewiss von Bedeutung, dass die Convergenzbewegung durch den Oculomotorius zu Stande kommt, die Divergenzbewegung nicht. Es dürte sich also um nichts Anderes handeln, als um eine bei jeder anf die Musc. recti interni combinirt ausgehenden Innervation gleichzeitig stattfindende Irradiation wie auf den Musc. ciliaris, so auch auf den $M$. sphincter iridis. 
Es kämen somit ganz andere Dinge in Betracht bei der Convergenz- und bei der Licht-Reaction. Und wie die Combinationen verschiedener Angenmuskeln in ganz verschiedener Weise verwendet werden, so dass wir gradezu zur Annahme verschiedener Coordinationscentren $z$. B. hier für einen Externus und Internus zusammen, hier für beide Interni zusammen genöthigt werden, so muss es sich auch für die beiden Arten von Pupillenverengerung um ganz getrennte Vorgänge und wahrscheinlich auch Localisationen handeln. Leider sind beweisende Experimente hierfür mit ganz ausserordentlichen Schwierigkeiten verknüpft, da Versuche über Convergenzreaction am Thier unmöglich sind.

Wir stehen also nicht völlig im Einklang mit $\mathrm{Erb}$, der meint, dass eine Störung auf der Seite des Oonlomotorius durch das Erhaltensein der Convergenzreaction direct auszuschliessen sei, da wir uns dieselbe auch bei einer solchen, wenigstens soweit sie eine centrale Faseranordnung beträfe, denken könnten - wir halten aber dennoch die Annahme einer selchen Störung deswegen für ungerechtfertigt, weil gar nichts Thatsächliches zu ihr drăngt und weil sie für die Erklärung der reflectorischen Pupillenstarre durchaus entbehrlich ist. - Wir können die Erb'sche Frklärung mit Hilfe einer zu supponirenden Störung im Reflexbogen zwischen Opticus and Oculomotorius adoptiren, aber nur in dem Sinn, dass nicht etwa auf einer solchen Bahn ein eigener materieller Erkrankungsheerd zu suchen wäre, sondern dass es sich nur um eine secundäre functionelle Störung handelt, deren primäre materielle Ursache weitab im Rückenmark liegt und nur dadurch auf das optico-oculomotorisehe Reflexverengerungscentrum der Pupille eine indirecte Wirkung ausübt, dass sie es allmählich ausser Function setzt in Folge des direct aufgehobenen Einflusses der dilatirenden antagonistischen Kräfte. Wie diese Wirkung 
nun zu Stande konmen kann, hätten wir näher zu untersuchen.

Geben wir von dem in seinen Bedingungen einfachsten -- für uns durchsichtigsten Fall aus, dem der peripheren partiellen einseitigen Sympathicuslähmung z. B. durch Struma, so haben wir hier den werthvollen Vergleich mit der gesunden Seite, der uns zeigt, dass auf der kranken nicht nur die Pupillenerweiterung im Dunkeln eine im Vergleich mangelhafte und träge ist, sondern auch die Promptheit der Verengerung auf Lichteinfall einen Defect zeigt bei beiderseitig gleicher Convergenzreaction. Ein derartiger Fall ist gegenwärtig in unserer Beobachtung. Die Pupille ist bei ihm in mittlerer Beleuchtung mittelweit und nur eine kaum wahrnehmbare Spur enger als rechts und die Abnormität tritt in der geschilderten Weise erst bei wechselnder Beschattung und Beleuchtung hervor; die Reaction ist nur vermindert, nicht völlig aufgehoben, weil die Läsion des Sympathicus offenbar eine nur ganz geringfugige ist; entsprechend ist auch im Gegensatz zu unseren obigen Fällen in der Weite der Relinalgefässe kein Unterschied zu constatiren.

Wenn wir diesen Fall als Paradigma einer Störung des Pupillengleichgewichtes aus sicher nachweisbarer Ursache betrachten können, und zwar hier durch eine Störung in der Uebertragung der erweiternden Finflüsse, so liegt auf der anderen Seite uns ein sprechender Fall vor von ausschliesslich durch Oculomotoriusstörung, also Wegfall verengender Kräfte, bedingter Alteration. Wir haben ganz speciell mit Bezug auf die uns interessirenden Verhältnisse bei einem Fall von Oeulomotoriuslähmung mit Ptosis und Lähmung sämmtlicher vom Oculomotorius innervirter Muskeln eine interessante Reihe von Versuchen und Beobachtungen gemacht.

Für gewöhnlich war die Pupille $3 \mathrm{~mm}$ weit. Auf grellste Beleuchtung mit intensivstem Sonnenlicht trat 
keine Verengung ein; die Convergenzreaction fehlt auf dem kranken Auge völlig, während sie auf dem gesunden noch sehr prompt besteht; im Dunkeln ist die Pupille nicht weiter als bei intensivster Beleuchtung. Eserin contrahirt sie ad maximum wie eine normale Pupille, Atropin erweitert sie nur in schwächster Weise. Stärkste sensible Reize, unerträglich schmerzhafte faradische Ströme bringen keine Pupillenreaction auf der kranken Seite hervor.

Man hat schon immer hervorgehoben, dass die Pupillenweite bei Oculomotoriuslähmung nie eine der Atropinmydriasis gleichkommende ist. Man könnte sich allerdings darüber wundern, wenn man die Effecte des aufgehobenen Oculomotoriuseinflusses rein nur nach dem Schema des Ausfalls der verengenden Kraft betrachtet, nach deren Ausfall alsdann die gar nicht tangirte erweiternde, unausgesetzt einseitig wirkte. Dass die Sache jedoch so einfach nicht liegt, beweisen eben alle bisher gemachten Beobachtungen und einen Grund dafür kann uns eine genauere Analyse unseres Falles in genügender Weise an die Hand geben.

Zuerst haben wir auch an dieser Stelle uns mit dem möglichen Einwand zu befassen, dass spastische Zustände dem Verhalten der Pupille zu Grunde liegen. Es würde sich dabei, wie wir das oben darzuthun versucht haben, um einen Spasmus in einer Mittelstellung handeln, der nun hier noch ganz besonders unwahrseheinlich gemacht wird dadurch, dass Eserin ihn prompt modificirt. Bezüglich der weiteren Unwahrscheinlichkeit weisen wir auf das anlässlich der reflectorischen Pupillenstarre bei mittelweiten Pupillen Gesagte zurück. Handelt es sich nun aber hier um einen Lähmungszustand, so liegt dessen Ursache nachweisbar im Oculomotorius. Die Uebertragung cerebraler Einflüsse auf die Pupille ist durch Leitungsstörung seiner Bahn, die auch den Reflexbogen mit dem Opticns betreffen, aufgehoben. Eserin wirkt aber noch 
prompt: der Muskel oder periphere Nervenendigungen können normal erregt werden. Warum wirkt aber Atropin so schwach? Es ist eine wohlbegründete und allgemein angenommene Auffassung der Atropinwirkung, dass sie lähmend auf die peripheren Oculomotoriusendigungen wirkt. Dadurch kommt unter normalen Verhältnissen der reflectorisch verengende Einfluss auf die Pupille in Wegfall. Derselbe ist nun aber in unserem Falle schon duroh einen langsam zu Stande gekommenen Erkrankungsprozess allmählich ausgeschaltet worden, folghich kann die Atropinwirkung in dieser Richtung nicht viel Neues hinzufügen. Es spricht also dieser Befund bei Oculomotoriuslähmung entschieden zu Gunsten dieser Theorie der Atropinwirkung. Denn wenn es sich bei ihr um eine Reizung erweiternder Elemente handelte, so wäre diese ja in vollem Maasse möglich gewesen und nicht abzusehen, warum der Effect so gering ausfallt. Dagegen ist es klar, warum die Atropinmydriasis am normalen Auge in so hohem Maasse zu Stande kommt; die nun einseitig frei werdenden erweiternden Kräfte sind eben nur dadurch, dass sie ihres Antagonisten vorübergehend entledigt sind, disponirt, ihre volle Kraft zu entfalten. Wir lernen also von Seiten der Oculomotoriusstörung das Gleiche, was uns die Sympathicusstörung lehrt, nämlich dass Störung oder Ausschaltung einer antagonistischen Kraft im Laufe der Erkrankung die entgegengesetzte durchaus nicht etwa recht excessiv zur Geltung kommen lässt, sondern im Gegentheil diese veranlasst, ihre Thätigkeit mehr oder minder einzustellen. Dieses Verhältniss ist offenbar ein höchst zweckmässiges und sein Verständniss hängt zusammen mit dem des ganzen Pupillenmechanismus. Die beiden im Wettstreit befindlichen Kräfte erfüllen ihre Aufgabe vortrefflich so lange beide ungesehwächt wirken und man kann sagen, dass sogar jede derselben der Thätigkeit der anderen als eines Reizanstosses bedarf, wie besonders in anschaulicher 
Weise aus der Thatsache der oben geschilderten Oscillationen hervorgeht. Fallt dagegen nur eine Krafteinwirkung aus, so werden daraus höchst unzweckmässige und störende Verhältnisse hervorgehen. Denken wir uns den Eintritt einer solchen Störung plötzlich, wie bei einer Oculomotoriusdurchschneidung, so wird die Pupille allerdings, wenn die ersten von der Schnittstelle ausgehenden Reizerseheinungen völlig verschwunden sind, sehr weit werden müssen, dagegen giebt es nun gar keine Kraft, mehr, die antagonistisch wirkend das Geschäft der $\mathrm{Ab}$ blendung verrichtete, und der einzige Mechanismus, der hierfür geblieben, ist nur noch ein Nachlass des Innervationsvorganges in den erweiternden Bahnen. Derselbe muss nach einiger Zeit nothwendig eintreten; alsdann wird aber die Pupille nie mehr so enge, dass die erweiternden Kräfte besondere Reizanstösse erhielten; hiermit ist nun schon eine Mittellage gegeben, die allerdings nicht gleich so stabil bleibt.

Die eminente Zweckmässigkeit der Pupillarbewegung ist bis jetzt $z u$ einseitig nur für die Abblendungscontraction betont worden. Selbstrerständlich sind aber in einem System antagonistischer Kräfte beide gleichermassen positiv wirksam und stellt die dem Thätigkeitszustand der einen entsprechende Lage nicht einfach die Wirkung des Nachlassens der anderen dar. Dies ist für die Pupille völlig klar geworden seit dem Bekanntwefden der höchst wichtigen Thatsache der Pupillenerweiterung auf sensible Reize, besonders schön demonstrirbar im natürlichen und Chloroformschlaf, wo die in der Ruhe hochgradige Myosis nicht nur bei sensiblen Hautreizen, sondern auch bei akustischen in deutliche, vorubergehende Erweiterung übergeht. Aber auch den einfachen Fall, dass die Pupille immer mehr sich erweitert, je dichter das Dunkel der Ungebung wird, kőnnten wir ohne eine der Abblendungstendenz entgegengesetzte active Erweiterungstendenz nicht 
begreifen. Jene wird von der Retia aus, diese von allem, was nicht Retina ist, angeregt. Haut, Ohr, ferner Alles, was im Innern des Körpers sensibel ist, steht der Retina antagonistisch gegenüber. Ein Sinn und Zweck hiervon ist bei alleiniger Betrachtnng des Menschen kaum abzusehen. Was soll es für einen Zweck haben, wenn bei Wurmreiz, bei Brechact, bei Wehen die Pupillen weit werden? Es würde für den Menschen gewiss eine einfach den Lichtintensitätsverhältnissen entsprechende grössere oder geringere Pupillenweite vollständig genügen, zumal da ihm sicher die weite Pupille in optischer Hinsicht nichts nützt. Nun wird sie aber beim Menschen im Schreck extrem weit*), eine Erscheinung, die wohl auch eine Stutze an den erwähnten experimentellen Daten von Pupillenerweiterung bei Rindenreizung finden mag, die aber doch auch ihren Sinn haben muss. Ein solcher ergiebt sich leicht und ungezwungen bei der Betrachtung der Pupillenverhältnisse gewisser Thiere z. B. der Katze. Bekanntlich besteht bei ihr ein so grosser Unterschied zwischen den beiden Extremen, dex minimal engen Spalte der myotischen und des weiten Kreises der mydriatischen Pupille, dass an einen Nutzeffect nicht gezweifelt werden darf, nicht nur für die Verengerung der Abblendung wegen, sondern für die Erweiterung zur Gewinnnng einer grossen Lichtmenge zum Bessersehen in der Nacht. Unter diesen Gesichtspunkten wird die Pupillenerweiterung bei acustischen and sensiblen Reizen leicht verständlich, da alsdaun das Interesse, mehr Licht zu bekommen, immer grösser wird, sei es dass das Thier einen Verfolger oder eine Beute sehen will.

Bei der Störung des Antagonismus fällt die Intensität der Leistung anch des nicht primär betroffenen Antagonisten viel geringer aus, weil ihr Interesse ein geringeres

*) s. Darwin, Ausdruck der Gemüthsbewegungen. Deutsch von Carus. Stuttgart 1877. S. 278 vergl, bes. dort das Citat aas Grahiolet. 
geworden ist. Das betreffende Centrum weiss gewissermassen, dass seine Arbeit unnöthig geworden ist. Und so fehlt bei der spinalen Pupillenstarre mit Myosis auch die Pupillenverengerung auf Lichteinfall und werden uns auch die Fälle von reflectorischer Pupillenstarre bei mittelweiten oder weiten Pupillen verständlich, ja sogar vielleicht leichter verständlich, als die mit hochgradiger Myosis verbundenen, in denen wir eigentlich immer mehr Anfangszustände zu erblicken hätten;, wo das Oculomotoriuscentrum sich noch nicht den neuen Verhältnissen angepasst hat, vielleicht zunächst auch aus anderen Ursachen in demselben verlaufende Reizzustände annehmen können. Dass diese jedoch aus der blossen Thatsache einer eventuellen Stecknadelknopfmyosis allein nicht gefolgert werden dürfen, beweist die Schlafmyosis, die von aller Reizmyosis an Stärke nicht übertroffen wird, wie wir dies oben auseinandergesetzt haben. Wollte num endlich Jemand gegen unsere teleologische Betrachtung einwenden, dass ja möglicherweise die Pupillenerweiterung gar nicht anf Muskelaction, sondern nur auf Gefässwirkung beruhe, so hätten wir dagegen einfach zu bemerken, dass diese immerhin heutzutage unwahrscheinliche*) Annahme unsere Auffassung nicht berübren wird, für die der Mechanismus vermittelst dessen die erweiternden Kräfte in Action treten, gleichgültig ist; mit demselben Recht könnte Jemand die Zweckmässigkeit der Erection des Penis leugnen, weil sie ja nur durch Aenderung der Blutfüllung zu Stande komme.

Die Wirkung einer Störung auf den Antagonisten, zu deren Annahme wir durch die Thatsachen geführt werden, darf durchaus nicht verwechselt werden mit den interessanten

*) Wir haben bei unsern zahlreichen Versuchen mit Amylnitrit beim Menschen nie eine Pupillenveränderung gesehen und ebenso wenig bei speciell hieranf gexichteten an albinotischen Kaninchen, bei denen die Pupillenweite trotz einer deutlich sichtbaren starken Hyperämie der Iris unverändert blieb.

จ. Graefe's Arehiv für Ophthalmologie, XXVII. 3. 
Ergebnissen der Versuche verschiedener Experimentatoren (Hurwitz, Bessau, Vulpian, Tuwim), die fanden, dass eine gewisse Zeit nach der Durehschneidung des Sympathicus bei Kaninchen und speciell nach Exstirpation des Ganglion supremum die anfangs enge Pupille immer weiter und schliesslich weiter als die normale wird. Hier handelt es sich, wie auch aus den Ergebnissen einer directen Reizung der Iris hervorgeht und wie auch die genannten Autoren annehmen, um eine trophische Störung der Irismuskulatur, die am meisten den stärkst entwickelten Sphincter betrifft.

Im Lichte der Auffassung vom Antagonismus der die Pupillenweite und Reaction bestimmenden Kräfte bleibt keine der bei spinalen Erkrankungen factisch vorkommenden Pupillenstörungen unerklärlich, auch wenn wir an der Annahme ausschliesslich spinaler Erkrankangsheerde festhalten. Die Complication mit Amaurose kann selbstrerständlich die Pupille relativ weit machen durch Ausschaltung des Opticusreflexes auf den Oculomotorius. Sie könnte unter Umständen selbst eine spinale Myosis so ins Gegentheil umschlagen lassen, wofür wir jedoch keinen Fall besitzen, und was auch unwahrscheinlich ist, weil faktisch in zahlreichen Fällen von spinaler Amaurose, mit spinalen Pupillenphänomen complicirt die Pupille doch eng ist: ein weiterer schwerwiegender Beweis dafür, dass die Enge der Pupille am meisten ihrer Ruhelage entspricht. Wenn bei sicher spinalen Processen mit oder ohne Opticusbetheiligung hochgradige Mydriasis getroffen wird, so haben wir diese Combination, sofern sie spinaler Reizung entspringen könnte, schon oben besprochen. Häufiger aber wird in diesem Falle eine Erklärung aus rein spinaler Ursache nicht mehr möglich und ein Recurriren auf gleichzeitige Vorgänge an der Hirnrinde nöthig werden, welche oben schon besproehene Combination ja überaus häufig ist. 
3. Augenmuskeln.

Wenden wir uns schliesslich einer kritischen Betrachtung des letzten Bestandtheils der spinalen Symptomentrias am Auge zu, den in unserer Casuistik auch reichlich vertretenen Augenmuskellähmungen, so stehen wir hierbei wohl der dunkelsten Frage gegenüber. Zur Constatirung des thatsächlichen Verhaltens ist zu bemerken, dass auch unsere Fälle eine Bestätigung der allgemein acceptirten Annahme enthalten, dass Augenmuskellähmungen sehr früh im Verlauf von Rückenmarkserkrankungen auftreten, dass ferner der Trochlearis sehr selten oder nie befallen wird, Abducens und Oculomotorius in toto oder partiell in gleicher Häufigkeit, partiell letzterer häufiger als total. Ferner ist noch einer entschieden bei Rïckenmarkskrankheiten auch vorkommenden Ptosis durch Lähmung der glatten Muskelfasern mit oder ohne gleichzeitige Myosis Erwähnung zu thun.

Sehr fluchtiger Natur, oft wechselnd, überspringend bilden sich die spinalen Augenmuskellähmungen häufig spontan völlig zurück, während in anderen Fällen selbst die ausdauerndste Therapie ohnmächtig ist. Die Combinationen sind sehr vielseitig. Bald kann auf der einen Seite ein Oculomotoriusast, auf der anderen der Abducens gelähmt sein, sie betreffen aber nie ein coordinirtes System. Im Allgemeinen verhalten sich die Augenmuskelstorungen bei Syphilis und spinalen Erkrankungen auffallend ähnlich, nur sind vielleicht bei Syphilis complete Oculomotoriuslähmungen etwas häufiger.

So schwer auch die Erklärung der Augenmuskellähmungen aus rein spinalen Erkrankungen sein mag, so wird jedenfalls auch ihr Verständniss durch die Annahme gleichzeitiger cerebraler Heerde durchaus nicht erleichtert; denn die eben hervorgehobenen Momente würden sich sümmtlich sehr schlecht mit stabilen anatomisch nachweisbaren Erkrankungsheerden vertragen, die etwa in der Gegend der 
Oculomotoriuskerne oder der Vierhügel zu suchen wären. Eine von Hirnerkrankung abhängige isolirte Lähmung eines Oeulomotoriuszweiges ist allerdings für den zum Levator gehenden von corticalen Heerden her bekannt und eine solche begreift sich auch sehr wohl durch die anatomische Thatsache, dass in den centralsten Theilen die im Oculomotoriusstamm zusammengefassten Zweige wieder in ähnlicher Weise wie an der Peripherie auseinander treten. Hierher nun aber die betreffenden Heerde zu verlegen, wird niemand versuchen. Es kann nur bedauert werden, dass es fưr die Augenmuskellähmung noch keine directen. differentialdiagnostischen Momente zur Unterscheidung zwischen peripher oder central giebt, wie wir sie in der Elektrodiagnostik der übrigen Körpermuskeln besitzen. So bleibt man auf indirecte, mehr oder weniger unsichere Schlüsse aus Aetiologie u. ähnl. angewiesen. Da es unzweifelhaft durch Syphilis bedingte periphere Augenmuskellähmungen giebt, von denen zwar leider noch genaue anatomische Befunde fehlen, die aber doch am wahrscheinlichsten auf Gefüssveränderung and Entzündung, gummose Neubildungen am betreffenden Nervenzweig etc. beruhen, so würde auch für die symptomatisch ähnlichen spinalen Maskellähmangen am ungezwangensten in analoger Weise ein ahnlicher Vorgang angenommen werden. Bedenkt man ferner, dass auch zu den spinalen Fällen Syphilis einen grossen Procentsatz stellt und dass speciell in unserer Casuistik kein Fall von Augenmuskellähmung sich findet, in dem Syphilis sicher ausgeschlossen werden konnte, dagegen eine ganz erkleckliche Zahl, in der sie ganz notorisch ist, so läge gerade für die Augenmuskellähmungen, für sich betrachtet, entschieden die Theorie von einer gleichzeitigen Localisation eines Krankheitsprozesses unabhängig von einander am nächsten, zumal da für sie die Entstehung aus Rückenmarkstraumen und acuten Spinalaffectionen bis jetzt nicht bekannt ist. Andrerseits wird man freilich wieder 
frappirt von der engen Beziehung, die dieser Bestandtheil der ocularen Trias bei Spinalerkrankungen ebenso gut wie die beiden anderen mit dem Hauptleiden hat. Dagegen darf nicht verschwiegen werden, dass ein starker Beweis, der für das Abhängigkeitsverhältniss der Opticnserkrankung sprach, nämlich die ausnahmslose Doppelseitigkeit, hier im gleichen Maasse nicht gilt. Andererseits ergäben sich nun aber für die Augenmuskellähmungen wieder Anhaitspunkte für ein noch viel directeres Abhängigkeitsverhältniss vom Rückenmark, wollte man einige Thatsachen herbeiziehen, die dafür zu sprechen scheinen, dass Wurzeln der Augenmuskelnerven geradezu aus dem Ruckenmark aufsteigen. Hierfür haben wir erstens einmal, als auf eine wenn auch schwache experimentelle Stütze, zu verweisen auf die S. 153 oben angegebene Beobachtung. Auch haben wir von klinischer Seite zwei Fälle aus eigener Beobachtung beizubringen, in denen mit dem Symptomenbild einer auf die Cervikalanschwellung beschränkten Poliomyelitis anterior neben sonst völlig intakten Hirnnerven beidemale eine complete Lähmung eines Levator palpebrae bestand und zwar unverändert schon seit Jahren. Es wäre für diese Fälle gewiss am natürlichsten an eine Rückenmarksstelle zu denken, die mit der betreffenden Oculomotoriuswurzel in directer Beziehung stünde.

Nun lässt sich aber nicht leugnen, dass für unsere Fälle hiermit meistens sehr wenig erklärt wäre, besonders für solche, in denen sonst gar keine Erscheinungen einer uber das Lendenmark hinaufreichenden Erkrankung vorliegen und wo also entweder eine solche ad hoc bis ins Cervicalmark hinauf supponirt werden oder diesèn Nervenwurzeln eine ganz unberechenbar lange Bahn in das Rückenmark hinab gegeben werden müsste. Zudem würde es sich dann doch auch schliesslich um stabile centrale Lähmungsheerde handeln, nur dass sie im Rückenmark statt im Gehirn sässen. Für diese würde sich aber 
die gleiche Unwahrscheinlichkeit wie für jene ergeben. Unter diesen Verhältnissen können wir, wenn wir nicht überhaupt auf jeden Erklärungsversuch verzichten wollen, nur als eine directer Stütze sehr bedürftige Hypothese die im Einklang mit unserer sonstigen Auffassung stehende Vermuthung aussprechen, dass es sich auch bei den Augenmuskellähmungen um locale vasomotorische Störungen handelt, die wie dort den Nervus opticus so hier Augenmuskelnervenzweige beträfen und von primären Erkrankungsheerden im Rückenmark ausgiengen. Diese Erklärung würde allerdings viel weniger in der Luft stehen, wollte man sich überhaupt entsehliessen, bisher nur von einigen Seiten aus schüchtern gemachte Versuche allgemeiner anzuerkennen, nämlich die darauf hinzielenden, eine Reihe von cerebralen Störungen, die im Verlauf von Spinalerkrankungen beobachtet werden, durch vom Rückenmark ausgehende vasomotorische Einflüsse zu erklären.

Fin in diesem Sinne exquisit zu verwerthender Fall wäre dann folgender unserer Beobachtung:

C. Z., 48 J., Schreiner, rec. 8. October 1878.

Seit 2 Jahren "rheumatische" Beschwerden in Armen, Schultern, Beinen, Kreuzschmerzen. Urindrang. Seit drei Wochen Abnahme des Sehvermögens, Funkensehen.

R. A. H. 1,0 D. $S=\frac{1}{4}-\frac{1}{3}$.

L. A. H. 0,75 D. $S=\frac{1}{2}$.

Beiderseits maximale Myosis. Lichtreaction fehlt. Rothgrünblindheit.

Die Gesichtsfeldaufnahme ergab folgende Grenzen.

nach oben aussen resp.

R. I.

$\begin{array}{rrrrrr}\text { unten innen . . } & 0-180 & 50 & 55 & 30 & 55 \\ 20-160 & 55 & 25 & 40 & 50 \\ 40-140 & 65 & 25 & 45 & 50 \\ 60-120 & 70 & 30 & 50 & 60 \\ & 80-100 & 70 & 35 & 60 & 60 \\ 90-90 & 70 & 40 & 60 & 60\end{array}$


nach aussen unten resp.

R. L,

\begin{tabular}{|c|c|c|c|c|c|}
\hline innen oben & & $100-80$ & 65 & 55 & 60 \\
\hline & & $120-60$ & 50 & 30 & 60 \\
\hline & & $140-40$ & 70 & 35 & 60 \\
\hline & & $160-20$ & 60 & 40 & 50 \\
\hline
\end{tabular}

Beide Optici grauweiss. - Gefässe normal.

Patellarsehnenreflexe fehlen.

24. Oetober 1878. Nachts Sehwindelanfall mit Angstgefithl, ebenso am 25. mit anarthrischer Sprachstörung, Patient stösst mühsam die Worte aus, die er aussprechen will, im Finden der Worte keine Schwierigkeit. Intelligenz intact. Diese Anfälle wiederholen sich noch 5mal im Lauf des Tages, jedesmal völlige Unfähigkeit zu sprechen. Abends: Patient ist sehr hinfällig, kann sich kaum auf den Beinen halten Funken vor den Augen ,wie beim Galvanisiren".

Im weiteren Verlauf der Beobachtung treten diese Anfälle nicht mehr anf, die Sprache ist wieder normal. Patient klagt nur häufig über ein Gefühl von Pelzigsein in der linken Gesichtshälfte. Die rechte Körperhälfte ist trocken und kühl normal - die linke heiss, mit klebrigem Schweiss bedeckt, besonders im Gesicht. Puls beschleunigt 112. Stärkere Carotidenpulsation links. Die maximale Myosis besteht ohne Veränderung bis zar Entlassung.

Vom 30. October an verschwinden auch diese Zuständo völlig. 3. November auf Verlangen entlassen.

Die Aehnlichkeit dieses Falles mit den neuerdings im Progrès médical*) veröffentlichten ist frappant.

Erinnern wir uns nun noch, dass in nicht seltenen Fällen Gehörsstörungen bei Rückenmarksleiden vorkommen,

*) 1881 No. 31, 30. Juli. Sur les accidents bulbaires aigus observés dans la première période de l'ataxie locomotrice, par $J$ offroy et Hanot. Es sind zwei Beobachtungen, deren Resumé wir hier nach dem Original citiren wollen:

I. 1. Premiers symptômes d'ataxie: douleurs ataxiques à forme rhumatoïde, perversion du goût, bourdonnements d'oreilles. 2. Accidents bulbaires subits. Paralysie du voile du palais, parésie du pharynx, perversion du goût, anesthésie de la face, de la langue, paralysie faciale. 3. Symptômes confirmatifs de l'ataxie. Perte complête du réflexe tendineux des deux côtés, parésie vési- 
dass in einem Fall, der ausschliesslich spinale Symptome bot, der Geruch beiderseits völlig erloschen war und dass in einem anderen die Section die gleiche graue Degeneration wie an dem Opticus auch an dem Olfactorius nachwies, so eröffnet sich uns hierin eine Perspective auf möglicherweise noch viel weitergehende Abhängigkeitsverhältnisse, in denen intracranielle Organe zum Rückenmark stehen, als wir sie bis jetzt irgendwie sieher begründen könnten. Erst zahlreiche Sectionsergebnisse solcher Fälle mit der sicheren Möglichkeit gleichzeitige stationäre cerebrale Erkrankungsheerde bestimmt auszuschliessen, werden hier unzweideutige Schlüsse erlauben.

Schliesslich noch einige Bemerkungen über das Verhältniss der Syphilis zu unserem ganzen Capitel. Wir haben in unserer Casuistik in so vielen Fällen Lues gefunden, dass eine aus ihr gezogene Statistik die Annahme eines Causalzusammenhangs der chronischen Spinalkrankheiten (Tabes) mit Lues stützen müsste. Da auch eine schon leicht erkennbare Lues noch immer häufig übersehen wird und viel mehr noch eine versteckter liegende, so kann es nicht Wunder nehmen, dass Erb in dieser Hinsicht noch immer widersprochen wird - zudem manchmal auf Grund eines durch ehrwürdiges Alter ausgezeichneten Materials. Von jetzt ab datirende unbefangene Beobachtung

cale, perte de la puissance génitale, plaques d'anesthésie irrégulièrement disséminées sur tout le corps. 4. Traitement, disparition des symptômes bulbaires.

II. Surmenage. - Vertige. - Perte subite de l'usage des membres inférieurs. Paralysie faciale double. - Parésie de la langue. - Affaiblissement du goût. - Surdité incomplète à droite. - Signes manifestes d'ataxie locomotrice. - Amélioration rapide.

Die Verfasser bemerken in der Epikrise: "Par celà seul que ces symptômes bulbaires ne sont pas durables on ne peut guère les rattacher qu'à des modifications circulatoires probablement hyperémiques." 
wird sicher die Frage bald in Erb's Sinn entschieden haben.

Wichtig für uns ist dabei das Umgekehrte, dass wir uns nicht begnügen dürfen, bei einer hier in Betracht kommenden Augenaffection Lues zu constatiren und uns damit zufrieden zu geben, sondern nun erst recht zu fragen haben, ob sie nicht spinal vermittelt ist. Es handelt sich hier um Fälle, von denen wir nachstehend zwei instructive Beispiele geben:

1. Patient, 50 Jahre. Früher immer gesund. Vor 20 Jahren syphilitisch inficirt. Nachte mehrere Schmierkuren durch. In den Jahren 1874 und 1876 litt er häufig an „Rhenmatismen", wegen deren er in verschiedenen Kaltwasseranstalten behandelt wurde. $1878 \mathrm{kam}$ er zuerst in ophthalmologische Behandlung wegen einer Lähmung des linken Abducens; er wurde $\mathrm{zu}$ erneuter antisyphilitischer Behandlung nach Aachen geschickt. Nach der dortigen Cur zeigte sich Schwere und auffallende Müdigkeit in den Beinen. Im Sommer 1880 wurden zuerst von einem Neuropathologen das völlige Fehlen der Patellarsehnenreflexe, lancinirende Schmerzen, Gürtelgefühl, Crises gastriques constatirt. Im Frühjahr 1881 wurde, nachdem die Motilität des Auges ein Jahr lang völlig ungestört gewesen war, über Nacht der rechte Abducens völlig gelähmt. Patient kommt nun in neuropathologische und ophthalmologische Behandlung zugleich. Nach einem Monat hat unter electrischer Behandlung (besonders wirksam schien sich auch hier der faradische Pinsel nach Rumpf zu erweisen) die Abducenslähmung sich bedeutend gebessert. Nach 2 Monaten kommt Patient wieder, diesmal mit völliger Normalfunction der Muskulatur des rechten Auges, aber Lähmung des Internus links. Seine tabetisehen Symptome sind etwas geringer geworden, doch bestehen in neuerer Zeit wieder vermehrter Harndrang und das Gefühl von Zusammenselnüren im After besonders bei der Defäcation. Anfangs hatte man hier scheinbar nur eine syphilitische Augenmuskellähmung; der weitere Verlauf zeigte erst die versteckto Tabes incipiens.

2. Patient, 26 Jahre. Vor 5 Jahren lnetisch inficirt. Im Sommer 1881 wird ophthalmoskopisch beginnende graue Degeneration beiderseits constatirt mit normalem Gesichts- 
feld und völliger Rothgrünblindheit. Die damals gemachte weniger genaue Untersuchung auf spinale Symptome ergiebt keinen Anhaltspunkt für solche. Nach einer sehr energischen Sehmierkur wird bei gleichem ophthalmoskopischen Befund das Sehvermögen besser, die Farbenstörung bleibt.

Erneute Untersuchung des Allgemeinzustands im Sommer 1881 ergiebt Fehlen der Patellarsebnenreflexe, Iancinirende Schmerzen in beiden Ischiadicis, Schmerzpunkte an der Wirbelsäule, Crises gastriques. Grosse Müdigkeit und Abgeschlagenheit in den Beinen.

Auch hier hatte man sich Anfangs bei der Annahme einer syphilitischen Neuritis und Atrophie beruhigt.

Wir wollen natürlich damit, dass wir auf solche spinal vermittelte Fälle nachdrücklichst aufmerksam machen, die locale Entstehung syphilitiseher Opticus- und Augenmuskelaffectionen tuberhaupt durchaus nicht leugnen, und haben ja schon oben darauf hingewiesen, dass eine local entstandene luetische Neuritis durch Ablagerung reizender Producte in loco affectionis leicht erklärt werden könnte, ebenso auch durch directe pathologische Veränderungen der Gefässwände, nur glauben wir fordern zu müssen, dass diese Entstehungsweise erst angenommen werden darf, wenn jeder extraoculare nervöse Einfluss durch genaue Untersuchung sicher ausgeschlossen ist.

Denn dahin können wir alle unsere Untersuchungen zusammenfassen, dass ein bisher viel zu sehr vernachlässigtes Abhängigkeitsverhältniss des Auges von gefässregulirenden nervösen Einflüssen sich nachweisen lässt, das vollständig dem an die Seite zu setzen ist, in dem andere seiner Affectionen zu materiellen Erkrankungen des Circulationsapparates selbst stehen.*)

*) Vergl. hierfür besonders Michel, Das Verhalten des Anges bei Störungen im Oirculationsgebiete der Carotis. Festsehrift für Horner. Wiesbaden 1881. 